Accepted for publication in The Behavioral \& Brain Sciences, 9 September 2018

\title{
Précis of Cognitive Gadgets: The Cultural Evolution of Thinking
}

\author{
Cecilia Heyes \\ All Souls College \& Department of Experimental Psychology \\ University of Oxford \\ Oxford OX1 4AL \\ United Kingdom \\ cecilia.heyes@all-souls.ox.ac.uk \\ http://users.ox.ac.uk/ ascch/
}




\section{Abstract}

Cognitive gadgets are distinctively human neurocognitive mechanisms - such as imitation, mindreading, and language - that have been shaped by cultural rather than genetic evolution. New gadgets emerge, not by genetic mutation, but by innovations in cognitive development; they are specialised cognitive mechanisms built by general cognitive mechanisms using information from the sociocultural environment. Innovations are passed on to subsequent generations, not by DNA replication, but through social learning: people with a new cognitive mechanism pass it on to others through social interaction. And some of the new mechanisms, like literacy, have spread through human populations, while others have died out, because the holders had more students, not just more babies. The cognitive gadgets hypothesis is developed through four case studies, drawing on evidence from comparative and developmental psychology, experimental psychology and cognitive neuroscience. The framework employed, cultural evolutionary psychology, a descendant of evolutionary psychology and cultural evolutionary theory, addresses parallel issues across the cognitive and behavioural sciences. In common with evo-devo and the extended evolutionary synthesis, cultural evolutionary psychology underlines the importance of developmental processes and environmental factors in the emergence of human cognition. In common with computational approaches (deep learning, predictive coding, hierarchical reinforcement learning, causal modelling) it emphasises the power of general-purpose mechanisms of learning. However, cultural evolutionary psychology also challenges use of the behavioural gambit in economics and behavioral ecology, and rejects the view that human minds are composed of 'innate modules' or 'cognitive instincts'.

Keywords: cultural evolution; domain-specific/domain-general; evolutionary psychology; innateness; social construction; teleosemantics. 


\section{Introduction}

What makes us such peculiar animals? What is it about the human mind that has enabled us to transform our environments, to become so dependent on cooperation for survival, and thereby to construct the edifices of knowledge and skill in which our lives are embedded: craft, technology, agriculture, science, religion, law, politics, history, music, trade, art, literature, and sport? Contemporary answers assume that adult humans have mental faculties different from those of all other extant animals, and the differences have two sources - nature and nurture. Whether distinctively human faculties are understood to be symbolic or sub-symbolic, model-based or modelfree, general- or special-purpose, modular or holistic, optimal or Kluge-ridden, it is assumed that insofar as they do their jobs well it is because these faculties have been shaped by natural selection operating on genetic variants (nature) and by interaction between the neurocognitive system and its environment in the course of an individual's development (nurture).

Cognitive Gadgets: The Cultural Evolution of Thinking (Heyes 2018; henceforth Cognitive Gadgets in this Précis) argues that the most strikingly distinctive features of the human mind come from a third source - culture. Natural selection operating on cultural variants - traits inherited through social interaction - doesn't only give us beliefs, tools and techniques, it also produces new neurocognitive mechanisms. In a slogan: cultural evolution shapes not just what we think but how we think it. In a saintly metaphor: cultural evolution changes not only the grist but also the mills of the human mind (Aquinus 1272; Heyes 2012a). In a contrapuntal catchphrase: distinctively human cognitive mechanisms - such as language, theory of mind, causal reasoning, episodic memory, imitation, and morality - are not "cognitive instincts" (Pinker 1994) but "cognitive gadgets". These mechanisms, which are absent or merely nascent in other animals, were not designed by human minds but they are the products of human rather than genetic agency. They are gadget-like in being relatively small, but crucially important, parts of the mind. The bulk of our behaviour is controlled by 
mechanisms we share with other animals but cognitive gadgets are what make human minds and human lives so very odd.

Literacy is a cognitive gadget. The capacity to read print depends on dedicated neurocognitive mechanisms. Written language emerged only five to six thousand years ago, too recently in human history for the genetic evolution of neurocognitive mechanisms specialised for reading. Therefore, insofar as those mechanisms do their jobs well, it must be because they have been shaped by cultural evolution.

Cognitive Gadgets is an academic book written by a psychologist for accessibility to psychologists, neuroscientists, evolutionary biologists, anthropologists, archaeologists, computer scientists, economists, philosophers and others interested in human evolution. I worked hard to make it short, hoping it would be read even in disciplines where books are rare beasts. One of the consequences of brevity is that the logical geography in Chapter 1 is local. Focussing on closely related ideas in the recent past, Chapter 1 identifies the framework developed in the book as "cultural evolutionary psychology", a direct descendant of "evolutionary psychology" (Barkow, Cosmides \& Tooby 1995; Pinker 1994) and "cultural evolutionary theory" (Boyd \& Richerson 1988; Campbell 1965; Cavalli-Sforza \& Feldman 1981; Dennett 1990, 1991; Henrich 2015) (see Figure 1). Cultural evolutionary psychology is like evolutionary psychology in having the human mind as its explanatory target, and like cultural evolutionary theory in emphasising the importance of social learning as a force in human evolution, but it differs from both of these approaches in suggesting that distinctively human cognitive mechanisms get their adaptive characteristics from cultural rather than genetic evolution.

Viewed more broadly and with greater historical depth, the central thesis of Cognitive Gadgets addresses the modularity debate in cognitive science (Chomsky 1987; Fodor 1983; Samuels 2012), and discussions of functional specialisation in ethology (de Waal \& Ferrari 2010; Lorenz 1969), suggesting that, at least in humans, specialised cognitive mechanisms are built by general-purpose cognitive mechanisms; 'modules' are acquired (Karmiloff-Smith 1995). In making this case, 
Cognitive Gadgets joins the battle, initiated by the British Empiricists 300 years ago, over the power of general-purpose mechanisms of learning, siding with advocates of deep learning, predictive coding, hierarchical reinforcement learning, causal modelling, and Bayesians of almost every stripe (Lake, Ullman, Tenenbaum \& Gershman 2017). It also challenges use of the behavioural gambit in economics and behavioral ecology (Fawcett, Hamblin \& Giraldeau 2012; Nettle, Gibson, Lawson \& Sear 2013), discouraging a black box approach to neurocognitive mechanisms (Heyes 2016a), and builds on research in developmental psychology and elsewhere documenting the importance of cultural learning and cross-cultural variation in the way minds work (Haun et al. 2006; Legare \& Nielson 2015; Nisbett 2010; Shiraev \& Levy 2014; Tomasello 2009). At the broadest level, in common with evo-devo (West-Eberhard 2003, 2005), and the extended evolutionary synthesis (Laland et al. 2015), Cognitive Gadgets stresses the critical, formative roles of developmental processes and environmental factors in the emergence of human cognition.

Cognitive Gadgets has four foundational chapters (1-4), four case study chapters (4-8), each focussing on one cognitive gadget, and a concluding chapter (9).

\section{Nature, Nurture, Culture}

\subsection{Biological information}

The development of every aspect of human behaviour and cognition, like the development of all biological systems, depends on a rich, turbulent stew of factors. There are no pure cases of nature or of nurture; no biological characteristic is caused only by "the genes" or only by "the environment". Nonetheless, drawing on the teleosemantic conception of information (Millikan 1984; Shea 2013), I argue in Chapter 2 that psychologists and biologists can and should seek to isolate the contributions of nature (genetically inherited information), nurture (information derived from direct interaction between the developing system and its environment), and culture (information inherited via social interaction) to human cognitive development. Without this purpose 
and discipline there is a risk that 'explanations' of cognitive development will be no more than unwieldy descriptions, like Lewis Carroll's fictional map with a scale of one mile to one mile (see aside 2), or manageable only because they privilege some causes over others in an arbitrary way. Arbitrary privilege dominated the behavioral sciences of the twentieth century. As the pendulum swung from instinct theory (Kuo 1922) to behaviourism (Watson 1930), and back again to evolutionary psychology, via classical ethology (Lorenz 1965; Tinbergen 1963) and sociobiology (Wilson 1975), researchers fixated on nature, then on nurture, and finally put the genes back in the ascendant.

\subsection{Cultural evolution}

The importance of culture (sensu information inherited via social interaction) in shaping human behaviour has been emphasised by cultural evolutionists with increasing force since the 1980s (Boyd \& Richerson 1985; Campbell 1965; Cavalli-Sforza \& Feldman 1981; Henrich 2015; Morin, 2015; Sperber 1996). The idea of cultural evolution comes in three strengths: historical, populational, and selectionist (Figure 2; Brusse 2017; Godfrey-Smith 2009; Lewens 2015). When the term "cultural evolution" is used in the weakest historical sense it means nothing more than change over time in some characteristic that varies between human groups. The stronger populational conception assumes that large-scale changes of this sort - for example, changes in the distribution within a population of the use of particular technologies, or the consumption of certain foods - are the aggregate consequences of many episodes of social learning, of episodes in which individuals learn from others to use a particular technology or to eat a certain food. The strongest conception of cultural evolution, the selectionist view, shares the populational assumption and claims in addition that the conditions necessary for Darwinian or natural selection are present in the cultural domain: there are mechanisms for introducing variation, selection processes, and mechanisms preserving selected variants (Campbell 1974). Cognitive Gadgets pursues the selectionist approach because this approach has the potential to explain the adaptive character of distinctively human 
cognition mechanisms, why they do their jobs reasonably well. It assumes that genetic evolution and cultural evolution are based on the same variation-and-selective-retention heuristic, and proposes that, rather than being on a short "genetic leash" (Lumsden \& Wilson 2005: 144), cultural evolution is highly autonomous with respect to genetic evolution.

\subsection{Cultural evolution of cognitive mechanisms}

To apply a selectionist view of cultural evolution not only to beliefs and behaviour (the grist of the mind) but to cognitive mechanisms (the mills) it is necessary to identify variants, routes of inheritance, and mechanisms of inheritance.

Variants, or "traits", are the things to be quantified in calculations of fitness. In the case of mental grist, it is difficult to isolate variants in a principled way because the only guide is folk psychology. We are forced to consult common sense or intuition for hypotheses about where one belief ends and another begins; about whether a practice, such as eating spicy food, constitutes one behaviour or many. In contrast, cognitive science is a rich source of empirically-grounded hypotheses about variant cognitive mechanisms (mills). It stipulates that there is only one token of each type of cognitive mechanism in each brain, and distinguishes types of cognitive mechanism in a functional way, according to the kind of information it can process, and the computations and representations it uses to process the information. For example, in the dual-route cascade model of reading (Coltheart, Rastle, Perry, Langdon \& Ziegler 2001), a "reading aloud mechanism" is defined as a mechanism that can convert script into speech, and one reading aloud mechanism can differ from another in terms of the range of script sequences it can convert into speech (only regular, or regular and irregular words), and the types of representations (sensory and/or structured) it uses.

Routes of inheritance. The cultural inheritance of cognitive mechanisms, like that of beliefs and behaviour, can be vertical (from biological parents to their offspring), oblique (from individuals of one biological generation to genetically unrelated or distantly related individuals of the next generation), and/or horizontal (between individuals of the same biological generation) (Cavalli- 
Sforza \& Feldman 1981). The importance of each route may vary across cultures and types of cognitive mechanism, but a distributed pattern is likely to be common, in which all three routes see heavy traffic at different times in development. For example, in contemporary Western societies the foundations of mindreading - the capacity to ascribe thoughts and feelings - are laid in early childhood through interaction with parents (vertical; Slaughter \& Peterson 2012) and other members of the parental generation (oblique; Lewis, freeman, Kyriakidou, Maridaki-Kassotaki \& Berridge 1996). Later, when children and adults talk to one another about people's motivations and misapprehensions, and read literary fiction, the development of mindreading is influenced predominantly by peers (horizontal; Kidd \& Castano 2013).

Mechanisms of inheritance. It is risky to use words like "copying" and "transmission" to describe any mechanism of cultural inheritance. The processes that send beliefs and behaviour along the vertical, oblique and horizontal routes are seldom analogous to DNA replication (Heyes 2017a), and a cognitive mechanism is certainly not a pellet of information that can be copied inside your head, sent through the air, and planted wholesale in my head. Rather, cognitive mechanisms are culturally inherited through social interactions, sometimes with many agents over an extended period of developmental time; interactions that gradually shape a child's cognitive mechanisms so that they resemble those of the people around them. Reading is a clear example. Everyone agrees that children are typically taught to read, that literacy training produces new neurocognitive mechanisms, and that we do not genetically inherit specific predispositions to develop these mechanisms. Cultural evolutionary psychology merely draws attention to the fact that literacy training is a set of social interactions; interactions that provide demonstrations, instructions, feedback and encouragement, in formal and informal settings. If literacy training were achieved by planting a "reading chip" in each child's brain, the cultural inheritance of reading would be more like the genetic inheritance of eye-color, but it would not necessarily be more effective in preserving selected variants. 


\subsection{Nature, nurture, culture - in practice}

The final section of Chapter 2 turns to a practical question: By what empirical methods can we tease apart the contributions of nature, nurture, and culture to the development of cognitive mechanisms? I argue that the methods required are means of distinguishing "poverty of the stimulus" (Chomsky, 1965) from "wealth of the stimulus" (Ray \& Heyes 2011); cases in which the developmental environment provides too little (poverty) or at least enough (wealth) usable information to explain the properties of a cognitive mechanism. Poverty is a sign that the development of an adaptive cognitive trait depends on genetically inherited information (nature), whereas wealth is a sign that development depends on learning in a broad sense (nurture) and/or on culturally inherited information (culture). Where there is wealth, nurture is indicated when cognitive development varies with features of the environment in which development is actually occurring; with information that can be acquired by asocial learning, and by the kinds of social learning found in a broad range of animals. Culture is indicated when cognitive development varies with longer term features of the environment; features that may not be present when a particular individual is developing, or that can be acquired only via the kinds of social learning known as cultural learning.

Training studies can help to distinguish the roles of nature, nurture and culture (e.g. De Klerk, Johnson, Heyes \& Southgate, 2015; Lohmann \& Tomasello 2003), but most of the empirical methods with the power to parse cognitive development examine patterns of spontaneous covariation. They relate differences in cognitive ability to opportunities for learning and social learning across: 1) time points in development, 2) groups or individuals within a human population, 3) human populations, or 4) species. Examples of these methods are found in developmental psychology, cognitive psychology, cognitive neuroscience, behavioural genetics, cross-cultural psychology, and ethology, but there is currently a tendency in all of these fields to document cognitive variation without asking where it comes from, or laced with the assumption that nature is the dominant force. 


\section{Starter Kit}

Cognitive Gadgets suggests that the genetic starter kit for human cognition, although extensive, is very similar to the starter kits of other animals, including chimpanzees. In the course of hominin evolution, natural selection operating on genetic variants tweaked the mind in small but important ways. Genetic evolution has not given us programs for the development of powerful domainspecific cognitive mechanisms, such as mindreading and language, but it has made us friendlier than our primate ancestors; enhanced our attentional biases towards other agents; and expanded our capacities for domain-general learning and executive control. These are the "Small Ordinary" genebased changes that enable developing humans to upload "Big Special" cognitive mechanisms cognitive gadgets - from their culture-soaked environments (Heyes, 2018, pp. 52-53).

\subsection{Emotion and Motivation}

There is evidence that modern humans are more socially tolerant (less aggressive to conspecifics) and more socially motivated (more inclined to seek and value social rewards) than our primate ancestors, and that these propensities are due to genetic evolution. Some of the most striking evidence of heightened social tolerance comes from archaeological work showing that, in the last 200 thousand years, human skulls have undergone "craniofacial feminization" (Cieri et al. 2014). Combined with studies of domestication in a range of nonhuman species, including wolves (Darwin 1868; Wilkins, Wrangham \& Fitch 2014), these craniofacial changes suggest a reduction in androgen activity favored by genetic evolution because it made humans less likely to initiate and to elicit aggression from conspecifics. In the case of social motivation, there are signs that humans have an exaggerated, inborn tendency to enjoy "response-contingent stimulation" - events, typically social in origin, that are predicted or controlled by their own actions (Floccia, Christophe \& Bertoncini 1997). 
This may be due to upregulation of oxytocin, a neuropeptide that has been tweaked by genetic evolution in numerous ways over the last 700 million years (Roney, 2016).

Increments in social tolerance and motivation are quantitative changes in temperament, not the kind of thing one would normally expect to support a cognitive revolution. But they are important because they give developing humans access to a wide range of teachers and expert models, not only mothers, and incline them to act and think in any way that yields social rewards.

\subsection{Attention}

Social tolerance and motivation get developing humans up close and personal with a wide range of people who are equipped to fill and shape their minds with culturally inherited information.

Genetically inherited input biases ensure that, from birth, human children target their attention on these experts, ready to drink in the information they have to offer (Heyes 2003).

In common with many other animals, human newborns attend more to biological than nonbiological motion (Bardi, Regolin \& Simion 2011; 2014). Unlike other primate species, we also have inborn preferences for faces and voices. At birth, human babies turn their heads for longer to track a face-like triangle of dark blobs than an inversion of the same stimulus (Johnson, Dziurawiec, Ellis \& Morton 1991; Reid et al. 2017), and suck harder to hear speech sounds than synthetic sounds with similar pitch contour and spectral properties (Vouloumanos \& Werker 2007). In the first year of life both of these attentional biases become more specific. For example, the neonatal 'blob bias' becomes a preference for human over other primate faces at three months (Dupierrix et al. 2014), and for human faces making direction eye contact at four months (Vecera \& Johnson 1995). Gazecuing, a tendency to direct attention to the object or area of space in front of moving eyes, appears at two to four months (Hood, Willen \& Driver 1998), and between six and twelve months gaze-cuing becomes more selective and active: infants become more inclined to follow gaze when a gaze shift is preceded by direct eye-contact (Senju \& Csibra 2008), and to look back and forth between an adult's face and an object to check they have got the right spatial target (Carpenter \& Call 2013). 
Each stage in this developmental sequence makes infants more teachable by increasing the extent to which their attention is controlled by knowledgeable adults. Some researchers see a number of genetic adaptations coming on-line in the course of the sequence, including mindreading, but in Cognitive Gadgets I argue, using the parsing methods outlined in Chapter 2, that there is no compelling evidence for this view. As long as social rewards are more likely to follow direct eye contact than a glimpse of averted gaze, and as long as gaze shifts after eye contact better predict an encounter with an interesting object, reinforcement learning can build the full panoply of gaze-cuing phenomena on the foundation of a simple, genetically inherited face preference (Moore \& Corkum 1994; Paulus, Hunnius, Vissers \& Bekkering 2011; Triesch, Teuscher, Deak \& Carlson 2006).

\subsection{Cognition}

Associative learning is a set of domain-general processes, including stimulus-stimulus and reinforcement learning, which have been investigated using Pavlovian and instrumental conditioning procedures (Pearce 2013). Associative learning has been found in every vertebrate and invertebrate group where it has been sought, and in a wide range of functional contexts, from foraging to predator avoidance, mate choice and navigation (Heyes 2012b; MacPhail 1982; Shettleworth 2010). Comparisons across extant species suggest that genetic evolution has made some qualitative changes to associative learning in the course of its multi-million year history, fashioning it into a powerful method of tracking causal / predictive relationships between events (Dickinson 2012). There is no evidence that associative learning has undergone major, qualitative changes in the recent past, and certainly not in the hominin line, but it is likely that, compared with other apes, we are genetically prepared to forge associations faster, learn more of them in parallel, and more readily to attach associations to specific contexts (Fagot \& Cook 2006; Holland 1992).

When it was thought that associative learning controlled nothing more than "spit and twitches" (Rescorla 1988), our expanded capacity for this kind of domain-general learning seemed to have nothing to do with the peculiarity of human lives. However, recent work, much of it social 
cognitive neuroscience, indicates that associative learning plays a critical role in our capacities to teach and engage in group decision-making. For example, associative learning enables us to keep track of the relationship between a pupil's actions and their outcomes (Apps, Lesage \& Ramnani 2015), and to weight advice from another agent against our own experience (Behrens et al. 2008; Garvert, Moutoussis, Kurth-Nelson, Behrens \& Dolan 2015).

Although not as phylogenetically widespread as associative learning, executive functions inhibitory control, working memory, and cognitive flexibility - are also found in a range of species (Cook, Brown \& Riley 1985; MacLean et al. 2014; Matzel \& Kolata 2010). No one doubts that executive functions play a major role in human cognition, that they are more highly developed in humans than in other animals, or that a good deal of this expansion is due to nurture and culture (Diamond 2013). However, there is reason to believe that genetic evolution, nature, has also played a part in expanding the power, capacity and agility of executive function. The most widely cited evidence comes from neuroanatomical studies showing that the prefrontal cortex, which is focally involved in executive function, is disproportionately larger (Passingham 2008; Passingham \& Smaers 2014; Rilling 2014), and more extensively connected with phylogenetically older brain areas (Anderson \& Finlay 2014; Peterson \& Posner 2012; Zilles 2005), in humans than in chimpanzees.

\section{Cultural Learning}

Cultural evolutionary psychology is both a framework for research and a hypothesis. As a framework, it recognises that distinctively human cognitive mechanisms can be shaped by culturally inherited information, as well as by genetically inherited information and learning (Chapter 2). As a hypothesis, it proposes that cultural inheritance has played the dominant role in shaping all or most distinctively human cognitive mechanisms. To advance the hypothesis, Chapters 5-8 each look in detail at evidence relating to one type of distinctively human cognition: selective social learning, imitation, mindreading, and language. These are all varieties of cultural learning. 
Cultural learning is especially important for two reasons. First, both evolutionary psychologists and cultural evolutionary theorists, although divided on many issues, are united in assuming that the mechanisms of cultural learning are genetically inherited. Therefore, cultural evolutionary psychology warrants pursuit as a descendant of evolutionary psychology and cultural evolutionary theory only if there are good reasons to challenge this consensus. Second, from the perspective of cultural evolutionary theory, which I broadly share, mechanisms of cultural learning play a crucial role in making human lives so different from those of other animals. Like other distinctively human faculties, cultural learning meets challenges that arise in an individual's lifetime, enabling each of us to navigate the world of people (cf. face processing) and things (cf. causal understanding). However, unlike other faculties, cultural learning also underwrites a whole new inheritance system - cultural evolution. It is a gift that goes on giving. Cultural learning enables each person and social group to benefit from the accumulated experience of innumerable other people, past and present, and thereby collectively to acquire knowledge and to develop skills that are way beyond those of other species.

Cultural learning is typically understood to be a subset of processes known as "social learning", and social learning processes are thought to overlap with those of "asocial" or "individual" learning (e.g. Henrich 2015). This way of thinking, shown in Figure 3, has been shaped by the anthropologists, biologists, economists and mathematicians who have pioneered research on cultural evolution, and it has done some good service. However, from a cognitive science perspective, the framework in Figure 3 has two significant problems: 1) Cultural evolutionists tend to treat as "processes" phenomena that cognitive scientists would regard as "effects", i.e. as things to be explained, rather than things that do the explaining. They ignore the cognitive and neurological processes that produce observable changes in behaviour (Whiten \& Ham 1992). 2) Cultural learning is understood to be a "sophisticated subclass of social learning" (Henrich 2015, p.13), but there are no ground rules, empirical or conceptual, for deciding whether a particular type or example of social learning is or is not an example cultural learning. 
To enable dialogue between cultural evolutionary theory and cognitive science (Heyes 2017b), I propose a subtly different way of situating cultural learning, shown in Figure 4 . In this alternative framework, the superordinate category is "learning" - encoding for long-term storage information acquired through experience. When learning is assisted by contact with other agents it is called "social learning". When learning is not assisted by other agents, it is called "asocial learning" or "individual learning". "Cultural learning" is a subset of social learning involving cognitive processes that are specialised for cultural evolution - for example, that enhance the fidelity with which information is passed from one agent to another. This framework does not allude to "processes" in distinguishing asocial from social learning, and therefore avoids the misleading impression that social learning is known to depend on different cognitive mechanisms from asocial learning. Furthermore, although it makes the conventional assumption that cultural learning involves processes specialised for cultural inheritance, it does not embody any assumptions about how or why these processes are specialised. Rather, it is a framework for investigation of three questions that cultural evolutionists rarely tackle: 1 ) Cognition question - How do the mechanisms of cultural learning differ from those of social learning at the cognitive level? 2) Specialisation question - How have genetic evolution and/or cultural evolution contributed to the specialisation of cultural learning? 3) Contribution question - In what ways do the features that distinguish cultural learning from social learning contribute to cultural inheritance? For example, do they make "improved" cultural variants more likely than "unimproved" variants to be passed on?

Rather than appealing to "sophistication" - implying that we already know what is distinctive about the mechanisms of cultural learning at the cognitive level (question 1 above) - this framework defines cultural learning by ostension - by pointing at putative examples of cultural learning. The cultural learning box in Figure 4 lists the five categories of psychological phenomena (each containing behavioural effects and weakly specified cognitive processes) most commonly said by cultural evolutionists to be types of cultural learning: selective social learning (also known as 'learning biases', 'transmission biases', and 'social learning strategies'), imitation (called 'true 
imitation' when 'imitation' is used as a synonym for 'social learning'), teaching (or 'pedagogy'), mindreading (also called 'theory of mind', 'mentalising', 'shared intentionality', and 'social understanding'), and language (so good they named it once). These five categories are a natural place to start asking the cognition, specialisation, and contribution questions about cultural learning.

\section{Selective Social Learning}

In both of the schemes, shown in Figures 3 and 4, "social learning" names a rag bag of behavioral effects - from a snail following a slime trail, to a student reading about calculus - in which learning by one agent, the "observer" is influenced in some way by contact of some sort with another agent, the "model" or "demonstrator". Social learning is said to be selective primarily when the influence of the model varies with the circumstances of the encounter ("when" selectivity; e.g. greater influence when the observer's environment has recently changed, known as a copy when uncertain social learning strategy), or with some feature of the available models ("who" selectivity; e.g. greater influence by older than younger models, known as a copy older individuals social learning strategy).

Selective social learning has been a focus of cultural evolutionary studies since the 1980s, but it barely appears on the radar of cognitive scientists. Consequently, whereas Chapters 6-8 bring cultural evolutionary theory to bear on problems in cognitive science, Chapter 5 brings cognitive science into closer contact with cultural evolutionary theory. More specifically, Chapter 5 tackles head-on the cognition, specialisation, and contribution questions.

Addressing the cognition question, I suggest that most social learning is 1) mediated by the same, domain-general, associative processes as asocial learning, and 2) made selective by the same broadly attentional processes that make asocial learning selective. Four lines of evidence support the first of these hypotheses (Heyes 1994, 2012c): (i) Social and asocial learning ability covary. Among birds and primates, species and individuals that perform well in tests of social learning tend also to perform well in tests of asocial learning (Boogert, Giraldeau \& Lefebvre 2008; Bouchard, 
Goodyer \& Lefebvre 2007; Reader, Hager \& Laland 2011). (ii) Solitary animals are capable of social learning. In laboratory tests, animals such as red-footed tortoises (Wilkinson, Kuenstner, Mueller \& Huber 2010), which lead solitary lives in the wild, prove themselves adept at learning from social cues. iii) Social learning and asocial learning each come in the same three basic varieties - learning about single stimuli, about relationships among stimuli, and about relationships between stimuli and responses, or actions and outcomes (Heyes 1994; 2011) - and each type of social and asocial learning has been found in a wide range of species, including humans (Dawson et al. 2013; Leadbeater et al. 2015). (iv) Social learning bears the footprints of associative learning. For example, studies of human decision-making, combining mathematical modelling with functional brain imaging, have found that the same computations, based on the calculation of prediction error, are involved in processing information from social partners (social learning) and personal experiences of reward (asocial learning) (Behrens et al. 2008; Garvert et al. 2015; Hill, Boorman \& Fried 2016).

The second hypothesis suggests that, in most cases, social learning is selective by virtue of domain-general attentional processing, rather than domain-specific strategic processing. For example, when exposed to two potential models, observers attend more to one model than the other, and therefore learn more from one model than the other; they do not learn equally from both models and then, in a second stage of cognitive processing, decide which of the models they should trust to guide their own behaviour. Evidence consistent with this view comes from studies of selective social learning in children, adults and nonhuman animals (Heyes 2016a; Heyes 2016b; Heyes \& Pearce 2015). However - and here's the crucial part of my answer to the cognition question - in adults and children above the age of four or five years, there is evidence that some selective social learning is truly strategic; the observer chooses to trust one model rather than another by applying an explicit, metacognitive rule, such as copy the boat builder with the biggest fleet or copy digital natives (Fleming, Dolan, Frith 2012). In one such study, people made use of information from another agent-advice about which of two options to choose-to the extent that they believed the advisor to be motivated to help rather than to mislead them (Diaconescu, Mathys, 
Weber, Daunizeau, Kasper, Lomakina, Fehr \& Stephen 2014). These beliefs were explicitly stated, and the basic effect-covariation between the advisors' incentives and the participants' use of their advice - disappeared when participants were told that the advisors did not know which option they were recommending. Therefore, these results indicate that the participants used an explicitly metacognitive strategy such as copy when the model intends to help.

Thus, my answer to the cognition question is: the selective social learning mechanisms that are specialised for cultural inheritance, that constitute cultural learning, differ from other selective social learning mechanisms in being explicitly metacognitive; they represent 'who knows' in the form of conscious, reportable, domain-specific rules. If this is correct, then research on the development of metacognitive rules, showing that they are learned through social interaction (Bahrami et al. 2012; Güss \& Wiley 2007; Heine et al. 2001; Hurks 2012; Li, 2003; Mahmoodi et al. 2013; Mayer \& Träuble 2013), provides an answer to the specialisation question; it suggests that the selective social learning mechanisms that constitute cultural learning have been specialised by cultural evolution for cultural evolution. Consistent with this answer, there is a growing body of evidence of cross-cultural variation in the metacognitive social learning strategies used by adults (Efferson et al. 2007; Eriksson 2012; Henrich \& Broesch 2011; Mesoudi et al. 2015; Toelch et al. 2014). For example, in contrast with Westerners, Fijians are less likely to seek advice from people with more formal education (Henrich \& Broesch 2011), and, compared to Britons, people from mainland China engage in more social learning, and their social learning is less dependent on uncertainty (Mesoudi et al. 2015). Finally, my answer to the contribution question comes in three steps: 1) Metacognitive social learning strategies are able to focus social learning on knowledgeable agents with greater accuracy and precision because these strategies have been honed by cultural selection. 2) When knowledgeable agents can be identified accurately, individuals and social groups can afford to invest in the development of cognitive mechanisms enabling high fidelity cultural inheritance of skills. 3) High fidelity inheritance promotes cultural adaptation by reducing the number of models 
contributing to each new token of a cultural trait, and the degree to which the model's influence is contaminated by asocial learning (Godfrey-Smith 2012).

\section{Imitation}

Imitation is the longest serving category of cultural learning. Scientists have been claiming for more than a century that imitation involves complex computations specialized by genetic evolution for high fidelity cultural inheritance, and that this cognitive instinct plays a crucial role in allowing humans to make and use tools (Washburn 1908). Chapter 6 embraces the idea that imitation is 'special', but argues that it is made possible by a culturally inherited mechanism. The selling point of Chapter 6 is that it addresses head-on the question of how a new cognitive mechanism could be assembled in the course of ontogeny through social interaction.

Imitation occurs when observation of a model causes the observer to perform topographically similar behavior, i.e. behavior in which parts of the observer's body move in the same way, relative to one another, as parts of the model's body. Thus, the boy in Figure 5 is imitating the men, not because he is wearing similar clothes and heading in the same direction, but because parts of the boy's body, his arms and torso, are configured - spatially related to one another - in the same way as those of the men. Imitation has been assumed to involve complex, dedicated computations because in many cases, like that in Figure 5, it solves a thorny 'correspondence problem'. When the boy puts his hands behind his back, he doesn't see (or hear or feel) anything resembling what he sees (or hears or feels) when he looks at the men putting their hands behind their backs, and yet somehow the boy's cognitive system has produced an action that looks the same, that corresponds, from a third party perspective.

In the late 1970s, it was reported that newborn human babies can imitate a range of facial expressions and hand movements (Meltzoff \& Moore 1977). The reliability and validity of these findings have been questioned repeatedly (Anisfeld 1979, 2005; Jacobson \& Kagan 1979; Jones 2006, 
2007, 2009; Koepke, Hamm, Legerstee \& Russell 1983; Masters 1979; McKenzie \& Over 1983;

Meltzoff \& Moore 1979). However, replicated and extended in some laboratories, they have led to widespread acceptance of a theory suggesting that the correspondence problem is solved by a black box delivered by the genes. This cognitive instinct theory suggests that humans have an innate device that detects "equivalences between observed and executed acts", both encoded "supramodally" as "organ relations", but does not propose computations that would allow organ relations to be derived from observed body movements or cashed out as executed actions (Meltzoff \& Moore 1997). Thus, the cognitive instinct theory of imitation says there is a genetically inherited thing that solves the correspondence problem, but it does not say how the thing works. Identifying the 'thing' with mirror neurons (Lepage \& Theoret 2007) creates another black box. The question 'How do people imitate?' becomes the question 'How do mirror neurons imitate?'

The alternative, cognitive gadget, theory of imitation suggests that the correspondence problem is solved by 'matching vertical associations' - bidirectional excitatory links between sensory and motor representations of the same action, forged by associative learning during self-observation and specified types of sociocultural interactions (see Figure 6). This theory offers a mechanistic explanation for the imitation of both familiar actions (sometimes called 'mimicry') and novel actions (sometimes called 'true imitation' or 'observational learning'). In the latter case, it proposes that, via associative learning, matching vertical associations create a new cognitive mechanism by connecting two domain-general processes that normally operate independently. Matching vertical associations gear perceptual sequence learning, processes that encode the serial order of external stimuli, to motor sequence learning, processes that normally operate only when the agent is learning a new skill, such as riding a bike, through practice (Catmur, Walsh \& Heyes 2009; Heyes \& Ray 2000).

The cognitive instinct theory was recently undermined by a large-scale, longitudinal study of imitation in newborns, which reported negative results for all eleven gestures tested (Oostenbroek et al. 2016). In contrast, the gadget theory is supported by evidence of two kinds (for reviews see Catmur et al., 2009; Catmur, Press \& Heyes 2016; Cook, Bird, Catmur, Press \& Heyes 2014): Training 
studies involving adults, infants and nonhuman animals show that imitation - measured behaviourally and via 'mirror responses' in the brain - can be enhanced, abolished and reversed by novel sensorimotor experience. For example, adults usually do not imitate the actions of inanimate systems, such as robots, but after a brief period of training in which robotic movements are paired with topographically similar body movements performed by the observer, people imitate robots as much as they imitate other people (Press, Bird, Flach \& Heyes 2005). The second kind of evidence indicates that imitation, although flexible and adaptive, has the 'signature limits' (Butterfill \& Apperly 2013) one would expect if it is controlled by matching vertical associations. For example, imitation learning is effector-dependent; it does not readily generalise across parts of the body. People who have observed a complex sequence of key-pressing movements can reproduce the sequence when their fingers are in the same keyboard positions as the fingers of the model, but they cannot imitate the sequence when their hands are crossed on the keyboard (right hand operates left keys, and vice versa), or when they are asked to use their thumbs rather than their fingers to press the keys (Bird \& Heyes 2005; Leighton \& Heyes 2010).

The final section of Chapter 6 addresses five objections to the cognitive gadget theory of imitation, emphasising the following points. 1) Intervention versus development. Like most scientific evidence, the results of training studies - and related studies of expertise (e.g. Calvo-Merino et al. 2006) - support inference to the best explanation, not deduction (Lipton 2003). They favour the gadget theory over the instinct theory because they are exactly what the gadget theory predicts but difficult for the instinct theory to accommodate. 2) Homo imitans. Humans are more skilled and prodigious imitators than other animals, not primarily because they have better resources 'on the inside' (e.g. higher capacity mechanisms of associative learning), but because they have superior resources 'on the outside', cultural practices that support the acquisition of matching vertical associations. 3) Intentionality. A matching vertical association for an action, $x$, makes it possible, not obligatory, to imitate x. 4) Overimitation. Children's propensity to imitate instrumentally superfluous features of action (Lyons, Young \& Keil 2007) raises questions about the motivation, rather than 
ability, to imitate. Although the gadget theory is concerned with ability rather than motivation, it is broadly consistent with evidence that overimitation is due to reinforcement learning (Baer \& Sherman 1964; Garcia, Baer, \& Firestone 1971; Grusec \& Abramovitch 1982; Young, Krantz, McClannahan \& Poulson 1994). 5) What's the use? The gadget model raises the possibility that evolutionists have overlooked the most important function of imitation: high fidelity cultural inheritance, not of object-directed actions, but of communicative and gestural skills (Heyes 2013).

\section{Mindreading}

Mindreading, the ascription of mental states, is classed as a form of cultural learning because it is likely to be the 'special ingredient' of human teaching. Effective teaching involves many other cognitive and motivational ingredients, including social tolerance and attentiveness, but mindreading stands out as the most likely candidate for a human-specific cognitive adaptation for teaching.

The idea that mindreading is a genetic adaptation, a cognitive instinct, begins to be less compelling when one compares mindreading with print reading (literacy), a distinctively human cognitive mechanism that is known to be a product of cultural evolution (Heyes \& Frith 2014; see Section 1). For example, studies of neural specialization (Van Overwalle 2009), cultural variation (Shahaeian, Peterson, Slaughter \& Wellman 2011), and genetically heritable development disorders (autism; Frith 2001), have all been treated as evidence that mindreading is a cognitive instinct, and yet print reading shows comparable degrees of neural specialisation (Dehaene \& Cohen 2011) and cultural variation (Changizi, Zhang, Ye \& Shimojo 2006), and is associated with genetically heritable developmental disorders of its own (dyslexias; Paracchini, Scerri \& Monaco 2007).

At 5 years of age, monozygotic twins are no more alike than dizygotic twins in their mindreading ability (Hughes et al. 2005). This suggests "negligible genetic influence" and a powerful role for learning in the development of individual differences in mindreading, but it does not tell us 
what kind of learning is important. In principle it could be the kind of introspection-based learning emphasised by simulation theory; the science-like learning postulated by theory-theory, in which the child tests her self-generated hypotheses against a database of observed behavior; or, as gadget theory suggests, a form of cultural inheritance in which mindreading experts - parents and others instruct children about the mind, in conversation and by structuring developmental environments. In Chapter 7 of Cognitive Gadgets, I argue that evidence from natural experiments (Mayer \& Träuble 2013; Pyers \& Senghas 2009), observational studies (Meins 2012; Meristo, Hjelmquist \& Morgan 2012; O'Brien, Slaughter \& Peterson 2011; Slaughter \& Peterson 2012; Taumoepeau \& Ruffman 2006, 2008), and traditional experiments (de Villiers \& de Villiers 2012; Lohmann \& Tomasello 2003) favours the third of their possibilities. For example, in a natural experiment, deaf people who had been deprived of conversation about the mind, because they learned Nicaraguan Sign Language (NSL) when it included very few mental state terms, were less likely to pass a false belief test than a second cohort who had learned NSL later, when it contained a wider range of mental state terms (Pyers \& Senghas 2009). The first cohort was 10 years older than the second cohort; they had had 10 more years in which to introspect and test hypotheses. Therefore, if introspection or science-like learning, rather than conversation, was crucial for the development of mindreading, one would expect the first cohort to be better, not worse, at ascribing false belief.

Studies of "implicit mindreading", using eye-movement indices of behavior prediction, imply that nonhuman apes (Krupenye, Kano, Hirata, Call \& Tomasello 2016) and pre-linguistic infants (Kovács, Téglás \& Endress 2010; Onishi \& Baillargeon 2005) are capable of ascribing false beliefs. According to the "continuity" interpretation, implicit mindreading is due to the same, specialized cognitive mechanisms that mediate "explicit mindreading" in deliberating adults (Baillargeon, Scott \& Hu 2010). If the continuity interpretation is correct, mindreading could not be a cognitive gadget because it develops without (apes) and before (infants) conversation about the mind. However, two other interpretations of implicit mindreading are compatible with the cognitive gadget theory. According to the "two-systems" (Apperly 2010; Perner 2010) and "submentalizing" (Heyes 2014a, 
2014b, 2015, 2017b) interpretations, implicit and explicit mindreading depend on different cognitive mechanisms. The two-systems view proposes that the mechanisms mediating implicit mindreading are specialised for fast and efficient representation of mental states, while the submentalising view suggests that they are domain-general mechanisms, representing relatively low-level features of action stimuli - such as colour, shape, and movement - rather than mental states. Evidence that concurrent demands on executive function interfere with explicit mindreading (Bull, Phillips \& Conway 2008), but not with implicit mindreading (Qureshi, Apperly \& Samson 2010), and that people with autism can engage in explicit mindreading in spite of impairments in implicit mindreading, favour the two-systems and submentalising hypotheses over the continuity hypothesis (Senju, Southgate, White \& Frith 2009).

The cognitive gadget theory implies that children learn to read minds through language, and therefore appears to be in direct opposition to the Gricean view that ascription of mental states is a precondition for linguistic communication (Bloom 2000; Sperber \& Wilson 1995; Tomasello 2009). However, for two reasons, I suspect that the cognitive gadget theory and the Gricean view of language are reconcilable. First, Grice offered a rational reconstruction, rather than a psycholologically realistic account, of what is happening whenever people talk to one another (Sperber 2000). Second, Moore (2016; in press) has argued persuasively that Gricean communication can get off the ground - in evolutionary and developmental time - with minimal mindreading; all that is needed is "a basic understanding of others' purposive activities and desires [which I would characterise as knowledge of action-outcome relationships], operating in conjunction with some tracking what others had or had not seen [or viewed]" (p.19).

Thus, advancing an alternative to simulation theory and theory-theory, Chapter 7 argues that mindreading is culturally inherited; a cognitive gadget. Expert mindreaders communicate mental state concepts, and ways of representing those concepts, to novices. As the present generation of novices become expert, they pass on the knowledge and skill of mindreading to the next cultural generation. 


\section{Language}

I have been thinking about social learning, imitation, and mindreading for a long time but I write about language as an outsider. While developing the ideas in Cognitive Gadgets, I immersed myself for the first time in research on the origins of language, expecting to find clear evidence that language is a cognitive instinct - an instinct on which gadgets are built. Instead, I found a wealth of evidence that language is itself a gadget, and a divide between genetic and cultural evolutionists that no longer appears to be resolvable by empirical means.

Chapter 8 begins by contrasting a gradualist genetic theory of language evolution (Culicover \& Jackendoff 2005; Pinker 1994; Pinker \& Bloom 1990) with a cultural theory of language evolution (Christiansen \& Chater 2016), and then discusses evidence that should, or is widely thought to, support one of these theories over the other. The evidence relates to linguistic universals, critical periods, neural localisation, domain-general sequence learning, and social shaping.

Linguistic universals. There are few, if any, non-definitional features that all languages have in common (Evans \& Levinson 2009; Everett 2005; Jelinek 1995). However, this is compatible with the genetic theory when linguistic universals are construed not as features that all or many languages have in common, but as components of Universal Grammar, or a genetically inherited language of thought (Berwick \& Chomsky 2015). A "universal" in this sense need not be present in all or even most natural languages, and a feature that was found to be present in all languages would not necessarily be a universal (Boeckx 2009; Chomsky 1965; Pinker \& Jackendoff 2009)

Critical periods. Research with migrant populations and native speakers indicates that second language proficiency depends on number of years of exposure to the second language, rather than on whether learning began before or after puberty (Birdsong \& Molis 2001; Flege, YeniKomshian \& Liu 1999; Hakuta, Bialystok \& Wiley 2003), and that, with the exception of phonology (Werker \& Hensch 2015), first and second language learners may obtain similar levels of proficiency (Dabrowska,2012). These findings suggest that, contrary to the claims of some genetic theorists 
(Lenneberg 1967; Pinker 1994), grammar learning is not a critical period phenomenon. However, the critical period claim is not an original or essential part of the genetic account of the evolution of language.

Neural localisation. Language enlists a more widely distributed set of brain areas than any other major psychological function (Anderson 2008), and Broca's area is more often active during non-linguistic than linguistic tasks (Poldrack 2006). These data certainly tell against the idea that there is a 'language centre', but it is not clear why it was ever supposed that genetically inherited information is more likely than culturally inherited information to be found in a narrowly localised area of the brain (Cowie 2016; Lenneberg 1967; Pinker,1994).

Domain-general sequence learning. Computer simulation indicates that sequence learning, without inbuilt language-specific constraints, enables a system to process complex grammatical constructions in a human-like way (Christiansen \& MacDonald 2009). Experiments examining individual differences in typically developing adults and children suggest that they use the same sequence learning processes to learn artificial and 'real', linguistic grammars (Kidd 2012; Kidd \& Arciuli 2016; Misyak \& Christiansen 2012), and studies of people with 'Specific Language Impairment' indicate that their impairment is not, in fact, specific to language (Hsu \& Bishop 2014; Hsu, Tomblin \& Christiansen 2014; Tomblin, Mainela-Arnold \& Zhang 2007). Likewise, research with nonhuman animals confirms that domain-general sequence learning capacity has increased in the hominin line (Wilson, Slater, Kikuchi, Milne, Marslen-Wilson, Smith \& Petkov 2013), provides a plausible model of how this change has been implemented in the primate brain (BornkesselSchlesewsky et al. 2015; Ivanova et al. 2016), and supports evidence from humans that mutations of FOXP2 interfere with language by interfering with sequence learning more generally; that FOXP2 is not a 'language gene' (Reimers-Kipping, Hevers, Paabo \& Enard 2011; Schreiweis et al. 2014).

Social shaping. Research on social shaping suggests that infants and children are frequently corrected by adults when they make grammatical errors (Bohannon, MacWhinney \& Snow 1990; Demetras, Post \& Snow 1986; Moerk 1991), and that this negative input is put to use in language 
learning (Street \& Dabrowska 2010; Taumoepeau 2016). These findings, like those on sequence learning, confirm novel predictions of the cultural theory, and, in the case of social shaping, challenge Chomsky's "poverty of the stimulus argument", a foundation of the genetic account.

The genetic theory is proving remarkably resilient in the face of what appear to be empirical defeats (linguistic universals, critical periods, neural specialisation), and a tide of positive evidence supporting the cultural theory (sequence learning, social shaping). Some of this resilience may be due to the motility of the genetic theory. Chomsky's view has changed radically since the 1950s, but each of his successive approaches is represented in the current literature (Boeckx 2006; Crain, Goro \& Thornton 2006; Culicover \& Jackendoff 2005; Pinker \& Jackendoff 2005). The genetic theory is also insulated by the competence-performance distinction (Chomsky 1965), which enables its proponents to argue that, for example, research on sequence learning and social shaping bears on the externalisation of language (performance), but not on whether there is a genetically inherited language of thought (competence). Some of the resilience may even come from historically deep convictions about the significance of language; the genetic theory more fully preserves the idea that language is a Rubicon separating humanity from the beasts. As an outsider, I can only conclude that, while the genetic theory of language evolution is appealing for a variety of reasons, some of them extra-scientific, the cultural theory - once a poor relation - is now clearly specified and rich in empirical support.

\section{Cultural Evolutionary Psychology}

The final chapter of Cognitive Gadgets returns to some of the evolutionary questions in Chapter 2, now with concrete examples from the case studies, and discusses the prospects for a cultural evolutionary psychology.

Cultural group selection. Attempting to make the cognitive gadgets hypothesis as clear as possible, I try to spell out who benefits from the cultural selection of cognitive mechanisms, and the 
nature of the benefit. This analysis allows two types of multilevel selection (Damuth \& Heisler 1988; Okasha 2005), and uses imitation as an example (see Figure 7): Imagine a human population divided into two social groups, $\mathrm{X}$ and $\mathrm{Y}$, defined geographically or culturally, not by genes. Each person has an imitation mechanism, gearing motor sequence learning to perceptual sequence learning via matching vertical associations, Chapter 6 ). There are two versions of this mechanism, $M$ and $M^{\prime}$, and $\mathrm{M}^{\prime}$ is less common in $\mathrm{X}$ than $\mathrm{Y}$. The $\mathrm{M}^{\prime}$ version has a richer repertoire of matching vertical associations for whole body movements than the $M$ version, enabling people with $M^{\prime}$ more accurately to imitate actions involved in ritual (e.g. dance), hunting (e.g. stalking), and combat (e.g. spear throwing). As a consequence, bearers of $\mathrm{M}^{\prime}$ are better able than bearers of $\mathrm{M}$ to cooperate in a range of tasks (Heyes 2013; Tarr, Launay, Cohen \& Dunbar 2015; Tunçgenç \& Cohen 2016), and to sustain the cultural inheritance of techniques that enhance success in hunting and inter-group combat. These advantages lead groups in which the $\mathrm{M}^{\prime}$ mechanism predominates to acquire greater numbers of new members (Type 1 in Figure 7), or to produce more descendent groups (Type 2 in Figure 7), than groups in which M predominates.

Inheritance. The cultural inheritance of cognitive mechanisms involves social processes such as conversation, storytelling, turn-taking, collective reminiscing, teaching, demonstrating, and engaging in synchronous drills. For example, through conversation, teaching and demonstration children learn to deploy metacognitive social learning strategies in the same way as the people around them (Chapter 5). Through turn-taking in face-to-face interaction, and engaging in synchronous drills, children acquire a particular repertoire of matching vertical associations; they become able to imitate the same range of actions as their cultural parents (Chapter 6$)$. Through conversation, storytelling and collective reminiscing children become able to represent mental states, and accumulate a stock of generalisations about the way mental states relate to one another, to behaviour, and to the world (Chapter 7; Nile \& Van Bergen 2015; Salmon \& Reese 2016). Dedicated research of a radically new kind is needed to measure the robustness of these inheritance mechanisms. In advance of such research, three considerations suggest that they are robust enough 
to support cultural group selection of cognitive processes: 1) High fidelity replication is not a requirement for Darwinian selection (Godfrey-Smith 2012). 2) Redundancy is built into distributed inheritance (e.g. mindreading via vertical, horizontal and oblique routes). 3) Each social process of inheritance occurs repetitively, delivering multiple learning trials. Children are told a particular story not once but many times; different stories contain the same themes, morals and tropes; adults imitate the same facial gestures over and over again in face-to-face interaction with infants; collective reminiscence returns repeatedly to the same episodes.

Genetic assimilation. In principle, it is possible that new cognitive mechanisms start out as cognitive gadgets, constructed in the course of development through social interaction, but then selection progressively favors genetic mutations that reduce the experience-dependence of the gadgets' development, converting them into cognitive instincts (Henrich 2015). In practice, I have looked for, and failed to find, empirical evidence that this kind of genetic assimilation has occurred for example, evidence that learning is faster in natural than unnatural conditions, or that identical twins are more alike than fraternal twins. Cognitive gadgets may resist genetic assimilation because distinctively human cognitive mechanisms need to be nimble. Their job is to track specific, labile features of the environment, which move too fast for genetic evolution. For example, social learning strategies track 'who knows' in a particular social group, something that changes with shifting patterns in the division of labour and therefore of expertise. Imitation tracks communicative gestures, ritual movements and manual skills that change as groups find new group markers, bonding rituals, and technologies. And mindreading, like language, must not only track externally driven change in the phenomena it seeks to describe, but also self-generated change; alterations in the way the mind works caused by shifts in the regulative properties of theory of mind (McGeer 2007).

A little history. The cognitive gadgets hypothesis is a force theory rather than an historical theory; it is concerned with the processes involved, rather than the history of events, in human evolution. The ideal theory would be high on both the force and historical dimensions. Therefore, 
connecting the cognitive gadgets theory to key events in human evolution, using the archaeological record, is a priority for future research. Making a start down that road, and building on the "collective intelligence" hypothesis (Henrich 2004, 2015; Kline \& Boyd 2010; Muthukrishna \& Henrich 2016; Richerson \& Boyd 2013; Sterelny, in press), I suggest that climate-driven demographic changes, around 250,000 years ago, launched not only the cultural evolution of knowledge and skills, but also the cultural evolution of distinctively human cognitive mechanisms. The Small Ordinary components of the genetic starter kit were already in place (Chapter 3), and had been supporting cooperation and simple stone technologies for millions of years. Demographic changes allowed the Small Ordinary components to begin to be elaborated by cultural group selection into the Big Special mechanisms that we now identify as, for example, causal understanding, episodic memory, imitation, theory of mind and full-blown language.

Human nature. Cultural evolutionary psychology is consistent with an 'evolutionary causal essentialist' conception of human nature; a hybrid of the 'nomological account' (Machery 2008; in press) and 'causal essentialist' theory (Samuels 2012). On this view, human nature is the set of mechanisms that underlie the manifestation of species-typical cognitive and behavioural regularities, which humans tend to possess as a result of the evolution of their species, and, crucially, 'evolution' encompasses all selection-based evolutionary processes - genetic, epigenetic and cultural. The primary implication of evolutionary causal essentialism is that human nature is labile; it changes over historical rather than geological time. The first signs of literacy date from about 6000 years ago, and now the cognitive gadgets that enable people to read, being present in more than $80-90 \%$ of the global population, are part of human nature. On a broader scale, cultural evolutionary psychology implies that human minds are more agile, but also more fragile, than was previously thought. We are not stuck in the Pleistocene past with Stone Age minds, and new technologies - social media, robotics, virtual reality - provide the stimulus for further cultural evolution of the human mind, but we have more to lose. Wars and epidemics can wipe out, not just know-how, but the means to 
acquire that know-how. The capacity for cultural evolution, as well as the products of cultural evolution, could be lost.

Cultural evolutionary psychology. The idea at the core of Cognitive Gadgets - that distinctively human cognitive mechanisms are shaped by cultural evolution - is a bold, testable hypothesis. Of the mechanisms examined in the case studies, selective social learning provides the freshest opportunity for research by cognitive scientists. Beyond the case studies, there are many other mechanisms to be explored, including causal understanding and episodic memory. Moral reasoning is a priority because it is a form of cultural learning, and, being so intimately connected with emotion, has the potential to cast light on the co-evolution of cognitive and emotional gadgets (Barrett 2017).

One of the strengths of cultural evolutionary psychology is that it brings into sharp focus, and makes tractable, questions about how a new cognitive mechanism is put together over time. Evolutionary psychologists tend to assume that, if something is a cognitive instinct, it is the responsibility of some other discipline (perhaps genetics or paleo-archaeology), not cognitive science, to explain how it was constructed (Samuels 2004). In contrast, cultural evolutionary psychology encourages cognitive scientists, and others, to develop and test theories about gadget construction. Furthermore, because cultural evolution is faster than genetic evolution, and much of the construction process occurs within lifetimes, the cognitive gadgets theory makes questions about construction empirically tractable. They can be addressed, in collaboration with anthropologists and historians, by research involving contemporary and historical populations, as well as those for which we have only archaeological evidence. We don't have to guess how cognitive mechanisms were put together by genetic evolution in the Pleistocene past; through laboratory experiments and field studies, we can watch them being built in people alive today.

Cognitive Gadgets opens up a third way. It suggests that distinctively human cognitive mechanisms are adaptive because they are shaped primarily, not by nature or nurture, but by culture. I tried in the book to make this hypothesis clear and plausible, but I have no illusions that 
the case is already conclusive. A great deal more work is needed to test the cognitive gadgets theory, and, through the lens of cultural evolutionary psychology, to develop a deeper understanding of the origins and operating characteristics of human minds. 


\section{References}

Anderson, M. L. (2008). Circuit sharing and the implementation of intelligent systems. Connection Science, 20(4), 239-251.

Anderson, M. L., \& Finlay, B. L. (2014). Allocating structure to function: The strong links between neuroplasticity and natural selection. Frontiers in Human Neuroscience, 7, 918.

Anisfeld, M. (1979). Interpreting "imitative" responses in early infancy. Science, 205, 214-215.

Anisfeld, M. (2005). No compelling evidence to dispute Piaget's timetable of the development of representational imitation in infancy. In: S. Hurley \& N. Chater (Eds.), Perspectives on Imitation: From Cognitive Neuroscience to Social Science (Vol. 2), 107-131. Cambridge, MA: MIT Press.

Apperly, I. (2010). Mindreaders: The Cognitive Basis of "Theory of Mind." Psychology Press.

Apps, M. A., Lesage, E., \& Ramnani, N. (2015). Vicarious reinforcement learning signals when instructing others. Journal of Neuroscience, 35(7), 2904-2913.

Aquinas, T. (1272). Summa Theologica (New ed., 2015). Roccasecca, Italy: Xist Publishing.

Baer, D. M., \& Sherman, J. A. (1964). Reinforcement control of generalized imitation in young children. Journal of Experimental Child Psychology, 1, 37-49.

Bahrami, B., et al., (2012). Together, slowly but surely: The role of social interaction and feedback on the build-up of benefit in collective decision-making. J. Exp. Psychol. Hum. Percept. Per-form. $38,3$.

Baillargeon, R., Scott, R. M., \& He, Z. (2010). False-belief understanding in infants. Trends in Cognitive Sciences, 14(3), 110-118.

Bardi, L., Regolin, L., \& Simion, F. (2011). Biological motion preference in humans at birth: Role of dynamic and configural properties. Developmental Science, 14(2), 353-359.

Bardi, L., Regolin, L., \& Simion, F. (2014). The first time ever I saw your feet: Inversion effect in newborns' sensitivity to biological motion. Developmental Psychology, 50(4), 986. 
Barkow, J. H., Cosmides, L., \& Tooby, J. (Eds.) (1995). The Adapted Mind: Evolutionary Psychology and the Generation of Culture. Oxford: Oxford University Press.

Barrett, L. F. (2017). How Emotions are Made: The Secret Life of the Brain. Boston, MA: Houghton Mifflin Harcourt.

Behrens, T. E., Hunt, L. T., Woolrich, M. W., \& Rushworth, M. F. (2008). Associative learning of social value. Nature, 456(7219), 245-249.

Berwick, R. C., \& Chomsky, N. (2015). Why Only Us: Language and Evolution. Cambridge: MIT Press.

Bird, G., \& Heyes, C. (2005). Effector-dependent learning by observation of a finger movement sequence. Journal of Experimental Psychology: Human Perception and Performance, 31(2), 262-275.

Birdsong, D., \& Molis, M. (2001). On the evidence for maturational constraints in second-language acquisition. Journal of Memory and Language, 44(2), 235-249.

Bloom, P. (2000). How Children Learn the Meanings of Words. Cambridge: MIT Press.

Boeckx, C. (2006). Linguistic Minimalism: Origins, Concepts, Methods, and Aims. Oxford: Oxford University Press.

Bohannon, J. N., MacWhinney, B., \& Snow, C. (1990). No negative evidence revisited: Beyond learnability or who has to prove what to whom. Developmental Psychology, 26(2), 221-226.

Boogert, N. J., Giraldeau, L-A., \& Lefebvre, L. (2008). Song complexity correlates with learning ability in zebra finch males. Animal Behaviour, 76, 1735-1741.

Bornkessel-Schlesewsky, I., Schlesewsky, M., Small, S. L., \& Rauschecker, J. P. (2015). Neurobiological roots of language in primate audition: Common computational properties. Trends in Cognitive Sciences, 19(3), 142-150.

Bouchard, J., Goodyer, W., \& Lefebvre, L. (2007). Social learning and innovation are positively correlated in pigeons. Animal Cognition, 10, 259-266.

Boyd, R., \& Richerson, P. J. (1988). Culture and the Evolutionary Process. Chicago: University of Chicago Press. 
Brusse, C. (2017). Making do without selection-review essay of "Cultural Evolution: Conceptual Challenges" by Tim Lewens. Biology \& Philosophy, 32(2), 307-319.

Bull, R., Phillips, L. H., \& Conway, C. A. (2008). The role of control functions in mentalizing: Dual-task studies of theory of mind and executive function. Cognition, 107(2), 663-672.

Butterfill, S. A., \& Apperly, I. A. (2013). How to construct a minimal theory of mind. Mind \& Language, 28(5), 606-637.

Butterfill, S., Apperly, I., Rakoczy, H., Spaulding, S., \& Zawidzki, T. (2013). Symposium on S. Butterfill and I. Apperly, "How to Construct a Minimal Theory of Mind." _Mind and Language Symposia at the Brains Blog. http://philosophyofbrains.com/2013/11/11/symposium-on-butterfill-andapperlys-how-to-construct-a-minimal-theory-of-mind-mind-language-28-5-606-63.aspx

Calvo-Merino, B., Grèzes, J., Glaser, D. E., Passingham, R. E., \& Haggard, P. (2006). Seeing or doing? Influence of visual and motor familiarity in action observation. Current Biology, 16(19), 19051910.

Campbell, D. T. (1965). Variation and selective retention in socio-cultural evolution. Social Change in Developing Areas, 19, 26-27.

Campbell, D. T. (1974). Evolutionary epistemology. In: P.A. Schlipp (Ed.), The Philosophy of Karl Popper. LaSalle, IL: Open Court, 413-463.

Carpenter, M., \& Call, J. (2013). How joint is the joint attention of apes and human infants? Agency and Joint Attention, ??, 49-61.

Catmur, C., Press, C., \& Heyes, C. M. (2016) Mirror associations. In: R. A. Murphy \& R. C. Honey (Eds.), The Wiley Handbook of the Cognitive Neuroscience of Learning. Wiley.

Catmur, C., Walsh, V., \& Heyes, C. M. (2009). Associative sequence learning: The role of experience in the development of imitation and the mirror system. Philosophical Transactions of the Royal Society of London, Series B: Biological Sciences, 364(1528), 2369-2380.

Cavalli-Sforza, L. L., \& Feldman, M. W. (1981). Cultural Transmission and Evolution: A Quantitative Approach (No. 16). Princeton University Press. 
Changizi, M. A., Zhang, Q., Ye, H., \& Shimojo, S. (2006). The structures of letters and symbols throughout human history are selected to match those found in objects in natural scenes. The American Naturalist, 167(5), E117-E139.

Chomsky, N. (1965). Aspects of the Theory of Syntax. Cambridge, MA: MIT Press.

Chomsky, N. (1987) Modularity in sentence comprehensions. In: Modularity in knowledge representation and natural language understanding, ed. Garfield, MIT Press.

Christiansen, M. H. \& Chater, N. (2016). Creating Language: Integrating Evolution, Acquisition, and Processing. Cambridge: MIT Press.

Christiansen, M. H., \& MacDonald, M. C. (2009). A usage-based approach to recursion in sentence processing. Language Learning, 59(s1), 126-161.

Cieri, R. L., Churchill, S. E., Franciscus, R. G., Tan, J., Hare, B., Athreya, S., . . \& Wrangham, R. (2014). Craniofacial feminization, social tolerance, and the origins of behavioral modernity. Current Anthropology, 55(4), 419-443.

Coltheart, M., Rastle, K., Perry, C., Langdon, R., \& Ziegler, J. (2001). DRC: A dual route cascaded model of visual word recognition and reading aloud. Psychological Review, 108(1), 204.

Cook, R., Bird, G., Catmur, C., Press, C., \& Heyes, C. (2014). Mirror neurons: From origin to function. Behavioral and Brain Sciences, 37(2), 177-192.

Cook, R. G., Brown, M. F., \& Riley, D. A. (1985). Flexible memory processing by rats: Use of prospective and retrospective information in the radial maze. Journal of Experimental Psychology: Animal Behavior Processes, 11(3), 453.

Cowie, F. (2016). Innateness and language. In: E. N. Zalta (Ed.), The Stanford Encyclopedia of Philosophy. https://plato.stanford.edu/archives/win2016/entries/innateness-language.

Crain, S., Goro, T., \& Thornton, R. (2006). Language acquisition is language change. Journal of Psycholinguistic Research, 35(1), 31-49.

Culicover, P. W., \& Jackendoff, R. (2005). Simpler Syntax. Oxford: Oxford University Press. 
Dąbrowska, E. (2012). Different speakers, different grammars: Individual differences in native language attainment. Linguistic Approaches to Bilingualism, 2(3), 219-253.

Damuth, J., \& Heisler, I. L. (1988). Alternative formulations of multilevel selection. Biology and Philosophy, 3(4), 407-430.

Darwin, C. (1868). The Variation in Animals and Plants under Domestication. London: John Murray.

Dehaene, S., \& Cohen, L. (2011). The unique role of the visual word form area in reading. Trends in Cognitive Sciences, 15(6), 254-262.

De Klerk, C. C., Johnson, M. H., Heyes, C. M., \& Southgate, V. (2015). Baby steps: investigating the development of perceptual-motor couplings in infancy. Developmental Science, 18, 270280.

Della Libera, C., \& Chelazzi, L. (2006). Visual selective attention and the effects of monetary rewards. Psychological Science, 17(3), 222-227.

Demetras, M. J., Post, K. N., \& Snow, C. E. (1986). Feedback to first language learners: The role of repetitions and clarification questions. Journal of Child Language, 13(2), 275-292.

Dennett, D. C. (1990). Memes and the exploitation of imagination. The Journal of Aesthetics and Art Criticism, 48(2), 127-135.

Dennett, D. C. (1991). Consciousness Explained. Boston: Little, Brown \& Co.

De Villiers, P. A., \& de Villiers, J. G. (2012). Deception dissociates from false belief reasoning in deaf children: Implications for the implicit versus explicit theory of mind distinction. British Journal of Developmental Psychology, 30(1), 188-209.

De Waal, F. B., \& Ferrari, P. F. (2010). Towards a bottom-up perspective on animal and human cognition. Trends in Cognitive Sciences, 14, 201-207.

Diaconescu, A. O., Mathys, C., Weber, L. A., Daunizeau, J., Kasper, L., Lomakina, E. I., . . \& \& Stephan, K. E. (2014). Inferring on the intentions of others by hierarchical Bayesian learning. PLoS Comput Biol, 10(9), e1003810.

Diamond, A. (2013). Executive functions. Annual Review of Psychology, 64, 135-168. 
Dickinson, A. (2012). Associative learning and animal cognition. Philosophical Transactions of the Royal Society of London, Series B: Biological Sciences, 367(1603), 2733-2742.

Dupierrix, E., de Boisferon, A. H., Méary, D., Lee, K., Quinn, P. C., Di Giorgio, E., . . \& Pascalis, O. (2014). Preference for human eyes in human infants. Journal of Experimental Child Psychology, 123, 138-146.

Efferson, C., et al. (2007). Learning, productivity, and noise: An experimental study of cultural transmission on the Bolivian Alti-plano. Evol. Hum. Behav., 28, 11-17.

Eriksson, K. (2012). The nonsense math effect. Judgment Decis. Making 7, 746-749.

Evans, N., \& Levinson, S. C. (2009). The myth of language universals: Language diversity and its importance for cognitive science. Behavioral and Brain Sciences, 32(5), 429-448.

Everett, D. L. (2005). Cultural constraints on grammar and cognition in Piraha . Another look at the design features of human language. Current Anthropology, 46, 621-646.

Fagot, J., \& Cook, R. G. (2006). Evidence for large long-term memory capacities in baboons and pigeons and its implications for learning and the evolution of cognition. Proceedings of the National Academy of Sciences, 103(46), 17564-17567.

Fawcett, T. W., Hamblin, S., \& Giraldeau, L. A. (2012). Exposing the behavioral gambit: the evolution of learning and decision rules. Behavioral Ecology, 24(1), 2-11.

Flege, J. E., Yeni-Komshian, G. H., \& Liu, S. (1999). Age constraints on second-language acquisition. Journal of Memory and Language, 41(1), 78-104.

Fleming, S. M., Dolan, R. J., \& Frith, C. D. (2012). Metacognition: Computation, biology and function. Philosophical Transactions of the Royal Society, Series B: Biological Sciences, 367, 1280-1286.

Floccia, C., Christophe, A., \& Bertoncini, J. (1997). High-amplitude sucking and newborns: The quest for underlying mechanisms. Journal of Experimental Child Psychology, 64(2), 175-198.

Fodor, J. A. (1983) The Modularity of Mind. Cambridge: MIT Press.

Frith, U. (2001). Mind blindness and the brain in autism. Neuron, 32(6), 969-979. 
Garcia, E., Baer, D. M., \& Firestone, I. (1971). The development of generalized imitation within topographically determined boundaries. Journal of Applied Behavior Analysis, 4(2), 101-112.

Garvert, M. M., Moutoussis, M., Kurth-Nelson, Z., Behrens, T. E., \& Dolan, R. J. (2015). Learninginduced plasticity in medial prefrontal cortex predicts preference malleability. Neuron, 85(2), 418-428.

Giles, A., \& Rovee-Collier, C. (2011). Infant long-term memory for associations formed during mere exposure. Infant Behavior and Development, 34(2), 327-338.

Godfrey-Smith, P. (2009). Darwinian Populations and Natural Selection. Oxford: Oxford University Press.

Godfrey-Smith, P. (2012). Darwinism and cultural change. Philosophical Transactions of the Royal Society, Series B: Biological Sciences, 367(1599), 2160-2170.

Grusec, J. E., \& Abramovitch, R. (1982). Imitation of peers and adults in a natural setting: A functional analysis. Child Development, 636-642.

Güss, C. D., \& Wiley, B. (2007). Metacognition of problem-solving strategies in Brazil, India, and the United States. J. Cogn. Cult. 7, 1-25.

Hakuta, K., Bialystok, E., \& Wiley, E. (2003). Critical evidence: A test of the critical-period hypothesis for second-language acquisition. Psychological Science, 14(1), 31-38.

Haun, D. B. M., et al. (2006). Cognitive cladistics and cultural override in Hominid spatial cognition. Proceedings of the National Academy of Sciences of the United States of America, 103(46), 17568-17573.

Heine, S. J., et al. (2001). Divergent consequences of success and failure in Japan and North America: An investigation of self-improving motivations and malleable selves. J. Pers. Soc. Psychol. 81, 599.

Henrich, J. (2004). Demography and cultural evolution: How adaptive cultural processes can produce maladaptive losses: The Tasmanian case. American Antiquity, 69, 197-214. 
Henrich, J. (2015). The Secret of Our Success: How Culture is Driving Human Evolution, Domesticating Our Species, and Making Us Smarter. Princeton: Princeton University Press.

Henrich, J., \& Broesch, J. (2011). On the nature of cultural transmission networks: Evidence from Fijian villages for adaptive learning biases. Philos. Trans. R. Soc. Lond. B: Biol. Sci. 366, 11391148.

Heyes, C. M. (1994). Social learning in animals: Categories and mechanisms. Biological Reviews, 69(2), 207-231.

Heyes, C. M. (2003). Four routes of cognitive evolution. Psychological Review, 110(4), 713-727.

Heyes, C. M. (2011). Automatic imitation. Psychological Bulletin, 137, 463-483.

Heyes, C. M. (2012a). Grist and mills: On the cultural origins of cultural learning. Phil. Trans. R. Soc. B, $367,2181-2191$.

Heyes, C. M. (2012b). Simple minds: A qualified defence of associative learning. Philosophical Transactions of the Royal Society of London, Series B: Biological Sciences, 367(1603), 26952703.

Heyes, C. M. (2012c). What's social about social learning? Journal of Comparative Psychology, 126(2), 193.

Heyes, C. M. (2013). What can imitation do for cooperation? In: K. Sterelny, R. Joyce, B. Calcott, \& B. Fraser (Eds.), Cooperation and its Evolution. Cambridge, MA: M.I.T. Press, 313-331.

Heyes, C. M. (2014a). Submentalizing: I am not really reading your mind. Perspectives on Psychological Science, 9(2), 131-143.

Heyes, C. M. (2014b). False belief in infancy: A fresh look. Developmental Science, 17(5), 647-659.

Heyes, C. M. (2015). Animal mindreading: What's the problem? Psychonomic Bulletin \& Review, 22(2), 313-327.

Heyes, C. M. (2016a). Blackboxing: Social learning strategies and cultural evolution. Philosophical Transactions of the Royal Society, Series B, 371, 20150369. 
Heyes, C. M. (2016b). Who knows? Metacognitive social learning strategies. Trends in Cognitive Sciences, 20, 204-213.

Heyes, C. M. (2017a). Enquire within: Cultural evolution and cognitive science. Phil. Trans. R. Soc. B. Heyes, C. M. (2017b). Apes submentalise. Trends in Cognitive Sciences, 21(1), 1-2.

Heyes, C. M. (2018). Cognitive Gadgets: The Cultural Evolution of Thinking. Boston: Harvard University Press.

Heyes, C. M., \& Frith, C. D. (2014). The cultural evolution of mind reading. Science, 344(6190), 1243091.

Heyes, C. M., \& Pearce, J. M. (2015). Not-so-social learning strategies. Proceedings of the Royal Society of London, Series B: Biological Sciences, 282(1802), 20141709.

Heyes, C. M., \& Ray, E. D. (2000). What is the significance of imitation in animals? Advances in the Study of Behavior, 29, 215-245.

Hill, M. R., Boorman, E. D., \& Fried, I. (2016). Observational learning computations in neurons of the human anterior cingulate cortex. Nature communications, 7, doi:10.1038/ncomms12722.

Holland, P. C. (1992). Occasion setting in Pavlovian conditioning. Psychology of Learning and Motivation, 28, 69-125.

Hood, B. M., Willen, J. D., \& Driver, J. (1998). Adult's eyes trigger shifts of visual attention in human infants. Psychological Science, 9(2), 131-134.

Hsu, H. J., \& Bishop, D. V. (2014). Sequence-specific procedural learning deficits in children with specific language impairment. Developmental Science, 17(3), 352-365.

Hsu, H. J., Tomblin, J. B., \& Christiansen, M. H. (2014). Impaired statistical learning of non-adjacent dependencies in adolescents with specific language impairment. Frontiers in psychology, 5, 175.

Hughes, C., Jaffee, S. R., Happé, F., Taylor, A., Caspi, A., \& Moffitt, T. E. (2005). Origins of individual differences in theory of mind: From nature to nurture? Child Development, 76(2), 356-370. 
Hurks, P. P. M. (2012). Does instruction in semantic clustering and switching enhance verbal fluency in children? Clin. Neuropsychol. 26, 1019-1037.

Ivanova, M. V., Isaev, D. Y., Dragoy, O. V., Akinina, Y. S., Petrushevskiy, A. G., Fedina, O. N., . . \& \& Dronkers, N. F. (2016). Diffusion-tensor imaging of major white matter tracts and their role in language processing in aphasia. Cortex, 85, 165-181.

Jacobson, S. W., \& Kagan, J. (1979). Interpreting "imitative" responses in early infancy. Science, 205, 215-217.

Jelinek, E. (1995). Quantification in Straits Salish. In: E. Bach, E. Jelinek, A. Kratzer, \& B. Partee (Eds.), Quantification in Natural Languages. Kluwer, 487-540.

Johnson, M. H., Dziurawiec, S., Ellis, H., \& Morton, J. (1991). Newborns' preferential tracking of facelike stimuli and its subsequent decline. Cognition, 40(1), 1-19.

Jones, S. S. (2006). Exploration or imitation? The effect of music on 4-week-old infants' tongue protrusions. Infant Behavior and Development, 29, 126-130.

Jones, S. S. (2007). Imitation in infancy: The development of mimicry. Psychological Science, 18, 593599.

Jones, S. S. (2009). The development of imitation in infancy. Philosophical Transactions of the Royal Society, Series B: Biological Sciences, 364, 2325-2335.

Karmiloff-Smith, A. (1995). Beyond Modularity: A Developmental Perspective on Cognitive Science. Cambridge: MIT Press.

Kidd, D. C., \& Castano, E. (2013). Reading literary fiction improves theory of mind. Science, 342(6156), 377-380.

Kidd, E. (2012). Implicit statistical learning is directly associated with the acquisition of syntax. Developmental Psychology, 48, 171-184.

Kidd, E., \& Arciuli, J. (2016). Individual differences in statistical learning predict children's comprehension of syntax. Child Development, 87(1), 184-193. 
Kline, M. A., \& Boyd, R. (2010). Population size predicts technological complexity in Oceania. Proceedings of the Royal Society of London, Series B: Biological Sciences, 277(1693), 25592564.

Koepke, J. E., Hamm, M., Legerstee, M., \& Russell, M. (1983). Neonatal imitation: Two failures to replicate. Infant Behavior and Development, 6, 97-102.

Kovács, Á. M., Téglás, E., \& Endress, A. D. (2010). The social sense: Susceptibility to others' beliefs in human infants and adults. Science, 330(6012), 1830-1834.

Krupenye, C., Kano, F., Hirata, S., Call, J., \& Tomasello, M. (2016). Great apes anticipate that other individuals will act according to false beliefs. Science, 354(6308), 110-114.

Kuo, Z. Y. (1922). How are our instincts acquired? Psychological Review, 29(5), 344.

Lake, B. M., Ullman, T. D., Tenenbaum, J. B., \& Gershman, S. J. (2017). Building machines that learn and think like people. Behavioral and Brain Sciences, 40, e253.

Laland, K. N., Uller, T., Feldman, M. W., Sterelny, K., Müller, G. B., Moczek, A., Jablonka, E. \& OdlingSmee, J. (2015). The extended evolutionary synthesis: its structure, assumptions and predictions. Proc. R. Soc. B, 282(1813), 20151019.

Leadbeater, E. (2015). What evolves in the evolution of social learning? Journal of Zoology, 295(1), $4-11$.

Legare, C. H., \& Nielsen, M. (2015). Imitation and innovation: The dual engines of cultural learning. Trends in cognitive sciences, 19(11), 688-699.

Leighton, J., \& Heyes, C. M. (2010). Hand to mouth: Automatic imitation across effector systems. Journal of Experimental Psychology: Human Perception and Performance, 36(5), 1174.

Lenneberg, E. H. (1967). The Biological Foundations of Language. New York: Wiley.

Lepage, J. F., \& Théoret, H. (2007). The mirror neuron system: Grasping others' actions from birth? Developmental Science, 10(5), 513-523.

Lewens, T. (2015). Cultural Evolution: Conceptual Challenges. Oxford: Oxford University Press. 
Lewis, C., Freeman, N. H., Kyriakidou, C., Maridaki-Kassotaki, K., \& Berridge, D. M. (1996). Social influences on false belief access: Specific sibling influences or general apprenticeship? Child Development, 67(6), 2930-2947.

Lipton, P. (2003). Inference to the Best Explanation. Routledge.

Lohmann, H., \& Tomasello, M. (2003). The role of language in the development of false belief understanding: A training study. Child Development, 74(4), 1130-1144.

Lorenz, K. (1965). Evolution and the Modification of Behavior. Chicago: University of Chicago Press.

Lorenz, K. (1969). Innate bases of learning. In K.H. Pribram, On the biology of learning. New York: Harcourt, Brace \& World.

Lumsden, C. J., \& Wilson, E. O. (2005). Genes, Mind, and Culture: The Coevolutionary Process. World Scientific.

Lyons, D. E., Young, A. G., \& Keil, F. C. (2007). The hidden structure of overimitation. Proceedings of the National Academy of Sciences, 104(50), 19751-19756.

Machery, E. (2008). A plea for human nature. Philosophical Psychology, 21(3), 321-329.

Machery, E. (in press). A plea for human nature, redux. In: E. Hannon \& T. Lewens (Eds.), Why We Disagree about Human Nature. Oxford: Oxford University Press.

MacLean, E. L., Hare, B., Nunn, C. L., Addessi, E., Amici, F., Anderson, R. C., Aureli, F., Baker, J. M., Bania, A. E., Barnard, A. M., \& Boogert, N. J. (2014). The evolution of self-control. Proceedings of the National Academy of Sciences, 111(20), E2140-E2148.

MacPhail, E. M. (1982). Brain and Intelligence in Vertebrates. Oxford: Clarendon Press, 423.

Mahmoodi, A., et al. (2013). Learning to make collective decisions: The impact of confidence escalation. PLoS One, 8, e81195.

Masters, J. C. (1979). Interpreting "imitative" responses in early infancy. Science, 205, 215.

Matzel, L. D., \& Kolata, S. (2010). Selective attention, working memory, and animal intelligence. Neuroscience \& Biobehavioral Reviews, 34(1), 23-30. 
Mayer, A., \& Träuble, B. E. (2013). Synchrony in the onset of mental state understanding across cultures? A study among children in Samoa. Int. J. Behav. Dev. 37, 21-28.

McGeer, V. (2007). The regulative dimension of folk psychology. In: D. D. Hutto \& M. Ratcliffe (Eds.), Folk Psychology Re-Assessed. Springer, Netherlands, 137-156.

McKenzie, B., \& Over, R. (1983). Young infants fail to imitate facial and manual gestures. Infant Behavior and Development, 6, 85-95.

Meins, E. (2012). Social relationships and children's understanding of mind: Attachment, internal states, and mind-mindedness. In: M. Siegal \& L. Surian (Eds.), Access to Language and Cognitive Development. Oxford: Oxford University Press, 23-43.

Meltzoff, A. N., \& Moore, M. K. (1977). Imitation of facial and manual gestures by human neonates. Science, 198(4312), 75-78.

Meltzoff, A. N., \& Moore, M. K. (1979). Interpreting "imitative" responses in early infancy. Science, 205, 217-219.

Meltzoff, A. N., \& Moore, M. K. (1997). Explaining facial imitation: A theoretical model. Early Development \& Parenting, 6(3-4), 179.

Meristo, M., Hjelmquist, E., \& Morgan, G. (2012). How access to language affects theory of mind in deaf children. Access to Language and Cognitive Development, 44-61.

Mesoudi, A., et al. (2015). Higher frequency of social learning in China than in the West shows cultural variation in the dynamics of cultural evolution. Proc. Biol. Sci. 282, 20142209.

Millikan, R. G. (1984). Language, Thought, and Other Biological Categories: New Foundations for Realism. Cambridge: MIT press.

Misyak, J. B., \& Christiansen, M. H. (2012). Statistical learning and language: An individual differences study. Language Learning, 62(1), 302-331.

Moerk, E. L. (1991). Positive evidence for negative evidence. First Language, 11(32), 219-251.

Moore, C., \& Corkum, V. (1994). Social understanding at the end of the first year of life. Developmental Review, 14, 349-372. 
Moore, R. (2016). Gricean communication and cognitive development. The Philosophical Quarterly, $67,303-326$.

Moore, R. (in press). Social cognition, stag hunts, and the evolution of language. Biology \& Philosophy.

Morin, O. (2015). How Traditions Live and Die. Oxford: Oxford University Press.

Muthukrishna, M., \& Henrich, J. (2016). Innovation in the collective brain. Phil. Trans. R. Soc. B, 371(1690), 20150192.

Nettle, D., Gibson, M. A., Lawson, D. W., \& Sear, R. (2013). Human behavioral ecology: current research and future prospects. Behavioral Ecology, 24, 1031-1040.

Nile, E., \& Van Bergen, P. (2015). Not all semantics: Similarities and differences in reminiscing function and content between indigenous and non-indigenous Australians. Memory, 23(1), 83-98.

Nisbett, R. (2010). The Geography of Thought: How Asians and Westerners Think Differently ... and Why. Simon and Schuster.

O’Brien, K., Slaughter, V., \& Peterson, C. C. (2011). Sibling influences on theory of mind development for children with ASD. Journal of Child Psychology and Psychiatry, 52(6), 713-719.

Okasha, S. (2005). Multilevel selection and the major transitions in evolution. Philosophy of Science, 72(5), 1013-1025.

Onishi, K. H., \& Baillargeon, R. (2005). Do 15-month-old infants understand false beliefs? Science, 308(5719), 255-258.

Oostenbroek, J., Suddendorf, T., Nielsen, M., Redshaw, J., Kennedy-Costantini, S., Davis, J., . . \& \& Slaughter, V. (2016). Comprehensive longitudinal study challenges the existence of neonatal imitation in humans. Current Biology, 26(10), 1334-1338.

Paracchini, S., Scerri, T., \& Monaco, A. P. (2007). The genetic lexicon of dyslexia. Annu. Rev. Genomics Hum. Genet., 8, 57-79. 
Passingham, R. E. (2008). What is Special about the Human Brain? New York: Oxford University Press.

Passingham, R. E., \& Smaers, J. B. (2014). Is the prefrontal cortex especially enlarged in the human brain? Allometric relations and remapping factors. Brain, Behavior and Evolution, 84(2), 156166.

Paulus, M., Hunnius, S., Vissers, M., \& Bekkering, H. (2011). Imitation in infancy: Rational or motor resonance? Child Development, 82(4), 1047-1057.

Pearce, J. M. (2013). Animal Learning and Cognition: an Introduction. London: Taylor \& Francis.

Perner, J. (2010). Who took the cog out of cognitive science? In: P. A. Frensch \& R. Schwarzer (Eds.), Cognition and Neuropsychology: International Perspectives on Psychological Science (Vol. 1). London: Psychology Press, 241-261.

Petersen, S. E., \& Posner, M. I. (2012). The attention system of the human brain: 20 years after. Annual Review of Neuroscience, 35, 73-89.

Pinker, S. (1994). The Language Instinct: The New Science of Language and Mind (Vol. 7529). Penguin Press.

Pinker, S., \& Bloom, P. (1990). Natural language and natural selection. Behavioral and Brain Sciences, 13(4), 707-727.

Pinker, S., \& Jackendoff, R. (2005). The faculty of language: What's special about it? Cognition, 95(2), 201-236.

Poldrack, R. A. (2006). Can cognitive processes be inferred from neuroimaging data? Trends in Cognitive Sciences, 10(2), 59-63.

Press, C., Bird, G., Flach, R., \& Heyes, C. (2005). Robotic movement elicits automatic imitation. Cognitive Brain Research, 25(3), 632-640.

Pyers, J. E., \& Senghas, A. (2009). Language promotes false-belief understanding: Evidence from learners of a new sign language. Psychological Science, 20(7), 805-812. 
Qureshi, A. W., Apperly, I. A., \& Samson, D. (2010). Executive function is necessary for perspective selection, not Level-1 visual perspective calculation: Evidence from a dual-task study of adults. Cognition, 117(2), 230-236.

Ray, E., \& Heyes, C. (2011). Imitation in infancy: The wealth of the stimulus. Developmental Science, 14(1), 92-105.

Reader, S. M., Hager, Y., \& Laland, K. N. (2011). The evolution of primate general and cultural intelligence. Philosophical Transactions of the Royal Society, Series B, 366, 1017-1027.

Reid, V. M., Dunn, K., Young, R. J., Amu, J., Donovan, T., \& Reissland, N. (2017). The human fetus preferentially engages with face-like visual stimuli. Current Biology, 27, 1825-1828.

Reimers-Kipping, S., Hevers, W., Pääbo, S., \& Enard, W. (2011). Humanized Foxp2 specifically affects cortico-basal ganglia circuits. Neuroscience, 175, 75-84.

Rescorla, R. A. (1988). Pavlovian conditioning: It's not what you think it is. American Psychologist, 43(3), 151.

Richerson, P. J., \& Boyd, R. (2013). Rethinking paleoanthropology: A world queerer than we supposed. In: G. Hatfield \& H. Pittman (Eds.), Evolution of Mind, Brain, and Culture. Philadelphia: University of Pennsylvania Press, 263-302.

Rilling, J. K. (2014). Comparative primate neuroimaging: Insights into human brain evolution. Trends in Cognitive Sciences, 18(1), 46-55.

Roney, J. J. (2016). Theoretical frameworks for human behavioral endocrinology. Hormones \& Behavior, 84, 97-110.

Salmon, K., \& Reese, E. (2016). The benefits of reminiscing with young children. Current Directions in Psychological Science, 25(4), 233-238.

Samuels, R. (2004). Innateness in cognitive science. Trends in Cognitive Sciences, 8(3), 136-141.

Samuels, R. (2012). Science and human nature. Royal Institute of Philosophy Supplement, 70, 1-28.

Schreiweis, C., Bornschein, U., Burguière, E., Kerimoglu, C., Schreiter, S., Dannemann, M., . . \& \& Groszer, M. (2014). Humanized Foxp2 accelerates learning by enhancing transitions from 
declarative to procedural performance. Proceedings of the National Academy of Sciences, 111(39), 14253-14258.

Senju, A., \& Csibra, G. (2008). Gaze following in human infants depends on communicative signals. Current Biology, 18(9), 668-671.

Senju, A., Southgate, V., White, S., \& Frith, U. (2009). Mindblind eyes: An absence of spontaneous theory of mind in Asperger syndrome. Science, 325(5942), 883-885.

Shahaeian, A., Peterson, C. C., Slaughter, V., \& Wellman, H. M. (2011). Culture and the sequence of steps in theory of mind development. Developmental Psychology, 47(5), 1239.

Shea, N. (2013). Inherited representations are read in development. The British Journal for the Philosophy of Science, 64(1), 1-31.

Shettleworth, S. J. (2010). Cognition, Evolution, and Behavior. Oxford: Oxford University Press.

Shiraev, E., \& Levy, D. A. (2014). Cross-Cultural Psychology. Pearson Education Limited.

Slaughter, V., \& Peterson, C. C. (2012). How conversational input shapes theory of mind development in infancy and early childhood. In: M. Siegal \& L. Surian (Eds.), Access to Language and Cognitive Development. Oxford: Oxford University Press, 3-22.

Sperber, D. (1996). Explaining Culture. Oxford: Blackwell Publishers.

Sperber D. (2000). An objection to the memetic approach to culture. In Darwinizing Culture: the status of memetics as a science, pp. 163-174. Cambridge, UK: Cambridge University Press.

Sperber, D., \& Wilson, D. (1995). Relevance: Communication and Cognition. 2nd ed. Cambridge, UK: Cambridge University Press.

Sterelny, K. (in press). Culture and the extended phenotype: Cognition and material culture in deep time. In: A. Newen, L. de Bruin, \& S. Gallagher (Eds.), The Oxford Handbook of Cognition: Embodied, Embedded, Enactive and Extended. Oxford: Oxford University Press.

Street, J. A., \& Dąbrowska, E. (2010). More individual differences in language attainment: How much do adult native speakers of English know about passives and quantifiers? Lingua, 120(8), 2080-2094. 
Tarr, B., Launay, J., Cohen, E., \& Dunbar, R. (2015). Synchrony and exertion during dance independently raise pain threshold and encourage social bonding. Biology Letters, 11(10), 20150767.

Taumoepeau, M. (2016). Maternal expansions of child language relate to growth in children's vocabulary. Language Learning and Development, 12(4), 429-446.

Taumoepeau, M., \& Ruffman, T. (2006). Mother and infant talk about mental states relates to desire language and emotion understanding. Child Development, 77(2), 465-481.

Taumoepeau, M., \& Ruffman, T. (2008). Stepping stones to others' minds: Maternal talk relates to child mental state language and emotion understanding at 15, 24, and 33 months. Child Dev. 79, 284-302.

Toelch, U., et al. (2014). Individual consistency and flexibility in human social information use. Proc. Biol. Sci. 281, 20132864.

Tomasello, M. (2009). The Cultural Origins of Human Cognition. Cambridge: Harvard University Press. Tomblin, J. B., Mainela-Arnold, E., \& Zhang, X. (2007). Procedural learning in adolescents with and without specific language impairment. Language Learning and Development, 3(4), 269-293.

Triesch, J., Teuscher, C., Deák, G. O., \& Carlson, E. (2006). Gaze following: Why (not) learn it? Developmental Science, 9(2), 125-147.

Tunçgenç, B., \& Cohen, E. (2016). Movement synchrony forges social bonds across group divides. Frontiers in Psychology, 7, 782.

Van Overwalle, F. (2009). Social cognition and the brain: A meta-analysis. Human Brain Mapping, 30(3), 829-858.

Vecera, S. P., \& Johnson, M. H. (1995). Gaze detection and the cortical processing of faces: Evidence from infants and adults. Visual Cognition, 2(1), 59-87.

Vouloumanos, A., \& Werker, J. F. (2007). Listening to language at birth: Evidence for a bias for speech in neonates. Developmental Science, 10(2), 159-164.

Washburn, M. F. (1908). The Animal Mind. New York: Macmillan. 
Watson, J. B. (1930). Behaviorism. Chicago: Phoenix.

Werker, J. F., \& Hensch, T. K. (2015). Critical periods in speech perception: New directions. Annual Review of Psychology, 66, 173-196.

West-Eberhard, M. J. (2003). Developmental Plasticity and Evolution. Oxford: Oxford University Press.

West-Eberhard, M. J. (2005). Developmental plasticity and the origin of species differences. Proceedings of the National Academy of Sciences, 102(1), 6543-6549.

Whiten, A., \& Ham, R. (1992). On the nature and evolution of imitation in the animal kingdom: Reappraisal of a century of research. Adv Study Behav, 21, 239.

Wilkins, A. S., Wrangham, R. W., \& Fitch, W. T. (2014). The "domestication syndrome" in mammals: A unified explanation based on neural crest cell behavior and genetics. Genetics, 197(3), 795808.

Wilkinson, A., Kuenstner, K., Mueller, J., \& Huber, L. (2010). Social learning in a non-social reptile. Biology Letters, 6, 614-616.

Wilson, B., Slater, H., Kikuchi, Y., Milne, A. E., Marslen-Wilson, W. D., Smith, K., \& Petkov, C. I. (2013). Auditory artificial grammar learning in macaque and marmoset monkeys. Journal of Neuroscience, 33(48), 18825-18835.

Wilson, E. O. (1975). Sociobiology: The New Synthesis. Cambridge, MA: Harvard University Press. Young, J. M., Krantz, P. J., McClannahan, L. E., \& Poulson, C. L. (1994). Generalized Imitation and Response-Class Formation In Children With Autism. Journal of Applied Behavior Analysis, $27(4), 685-697$.

Zilles, K. (2005). Evolution of the human brain and comparative cyto- and receptor architecture. In: S. Dehaene, J. R. Duhamel, M. D. Hauser, \& G. Rizzolatti (Eds.), From Monkey Brain to Human Brain. Cambridge, MA: MIT Press, 41-56. 
Figure Captions

Figure 1. Relations between evolutionary psychology, cultural evolutionary theory, and cultural evolutionary psychology.

Figure 2. Relations between purely historical, populational, and selectionist conceptions of cultural evolution.

Figure 3. The received view of relations between individual learning, social learning, and cultural learning.

Figure 4. A framework for research on the relations between learning, social learning, and cultural learning, enabling dialogue between cognitive science and cultural evolutionary theory.

Figure 5. An example of imitation.

Figure 6. Matching vertical associations are acquired through sensorimotor learning. In the simplest case, self-observation (A), activation of a motor representation contributes to performance of an action (e.g. grasping; dotted arrow), and observation of the performed action produces correlated activation of a corresponding visual representation (dashed arrow). Correlated activation strengthens the excitatory link between the sensory and motor representations, establishing a matching vertical association (solid vertical line). Optical mirrors (B), being imitated by others (C), and synchronous activities (D) provide correlated sensorimotor experience for perceptually opaque actions, such as facial gestures and whole body movements.

Figure 7. Two types of fitness in cultural group selection. 
Figure 1

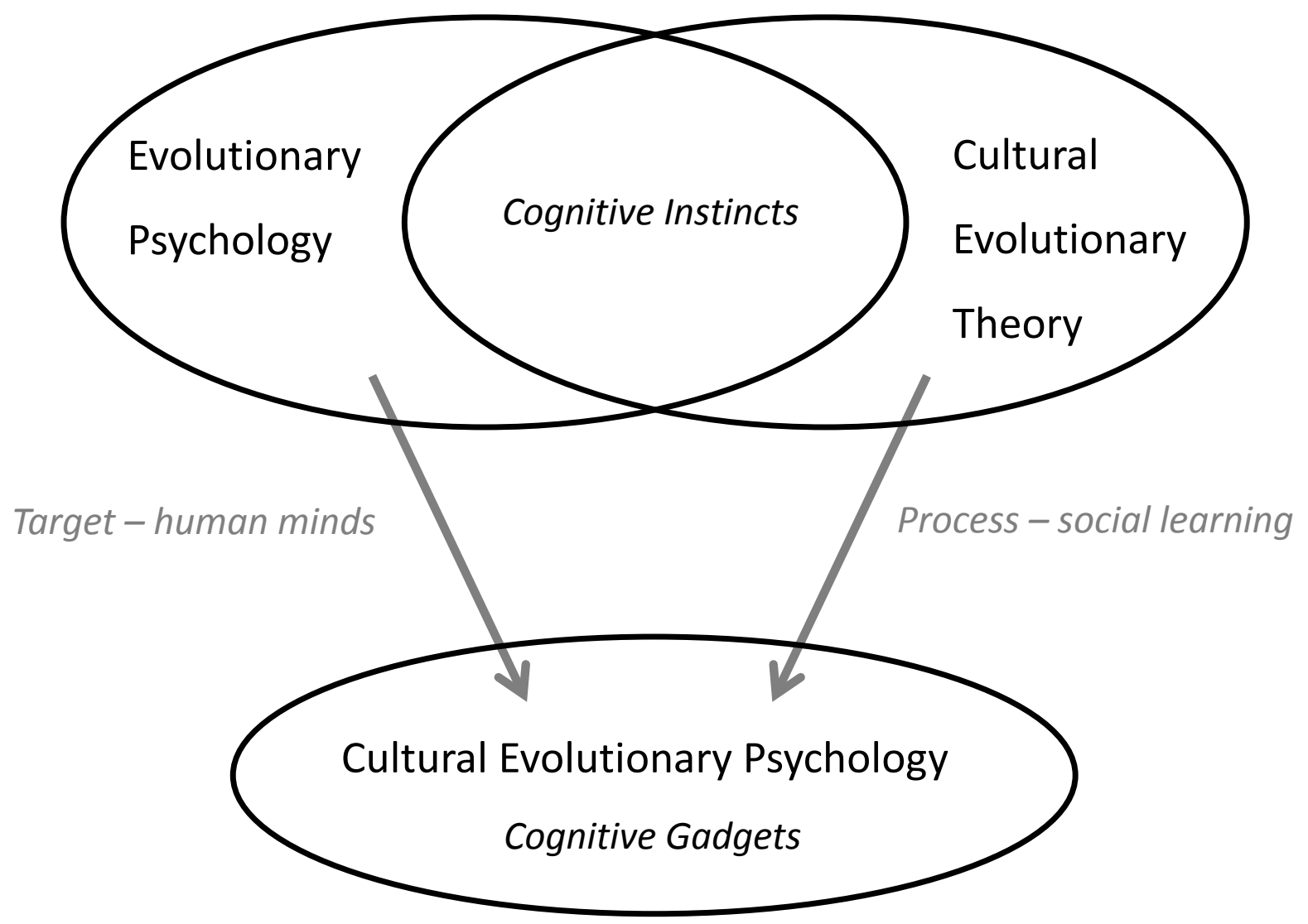


Figure 2

Historical

Populational

Selectionist 
Figure 3

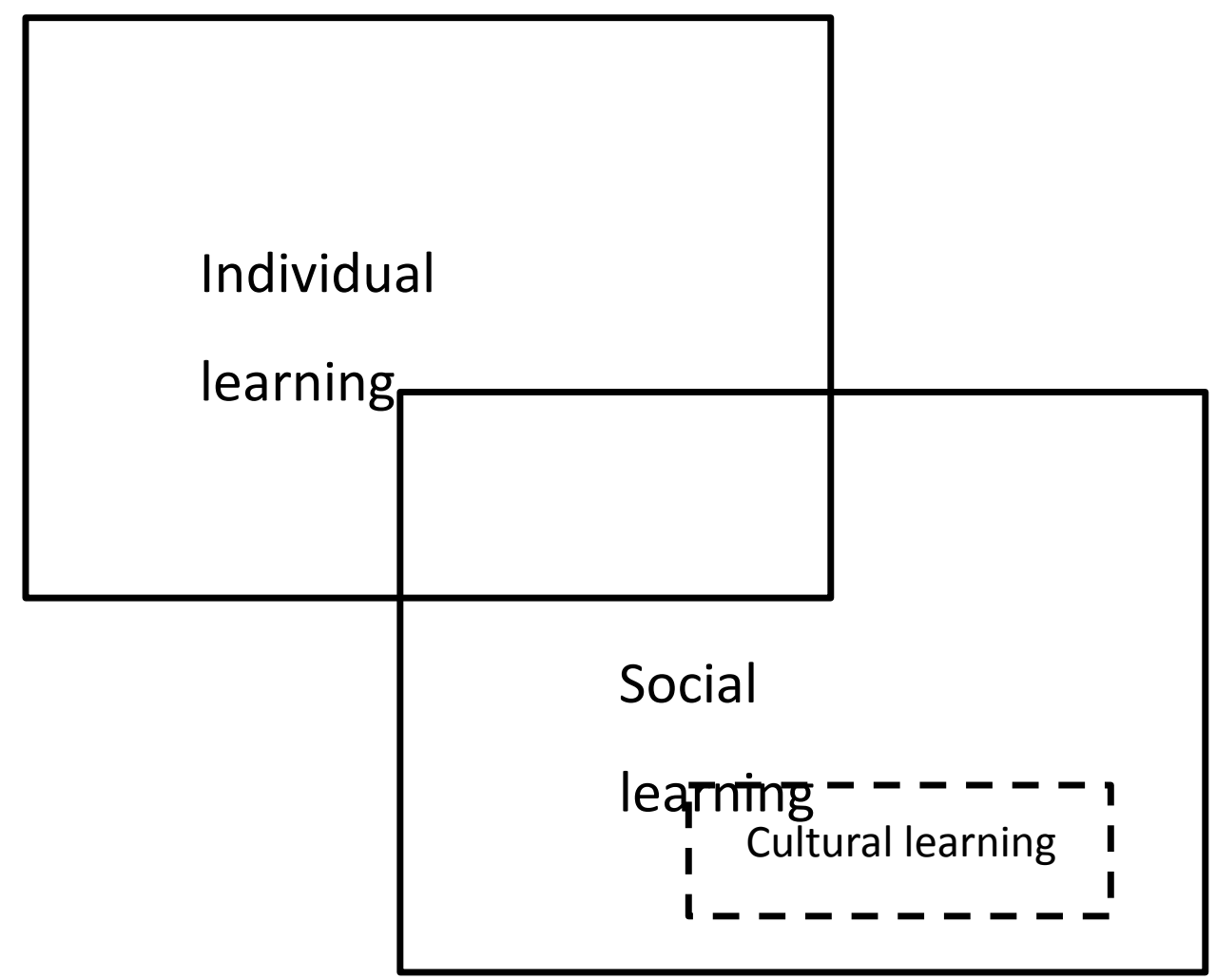


Figure 4

\section{Learning}

Encoding for long-term storage information acquired through experience

\section{Social learning}

Learning assisted by other agents

\section{Cultural learning}

Social learning specialised for cultural inheritance

Selective social learning

Imitation

Mindreading / Teaching

Language 
Figure 5

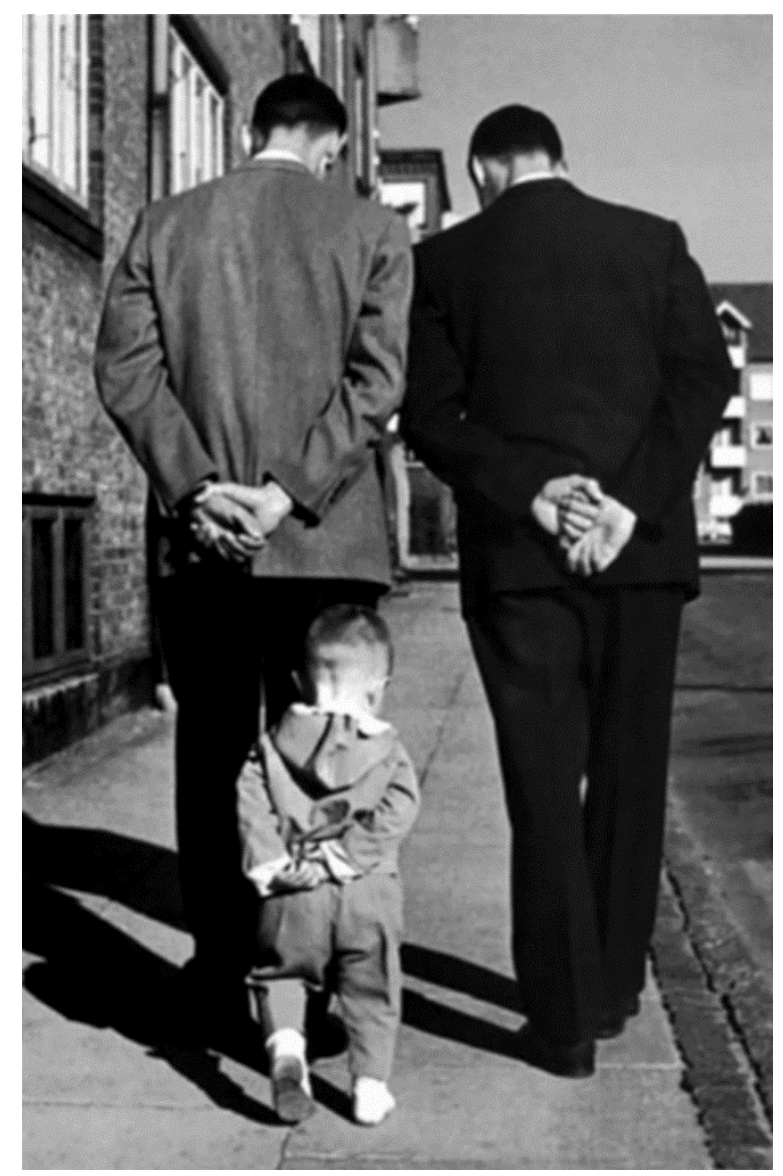


Figure 6

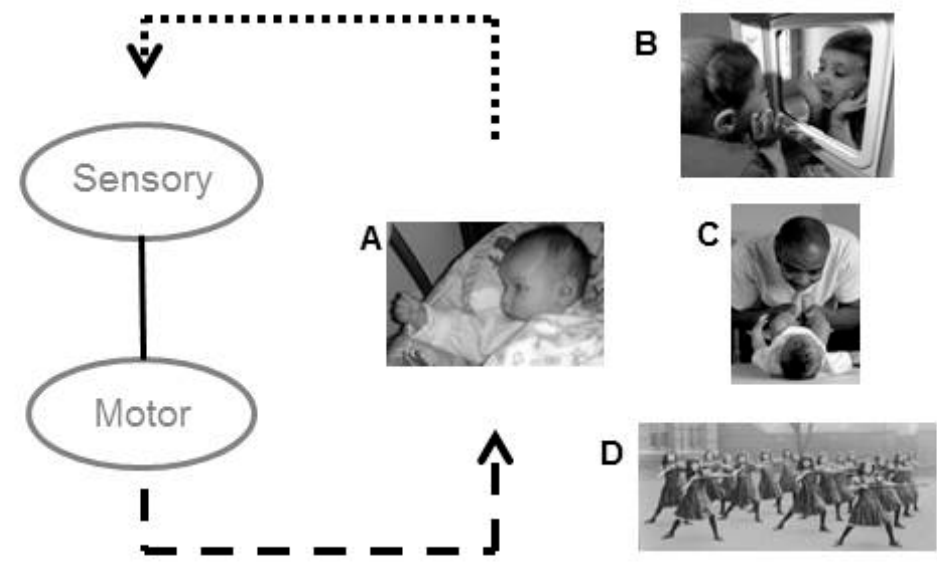


Figure 7
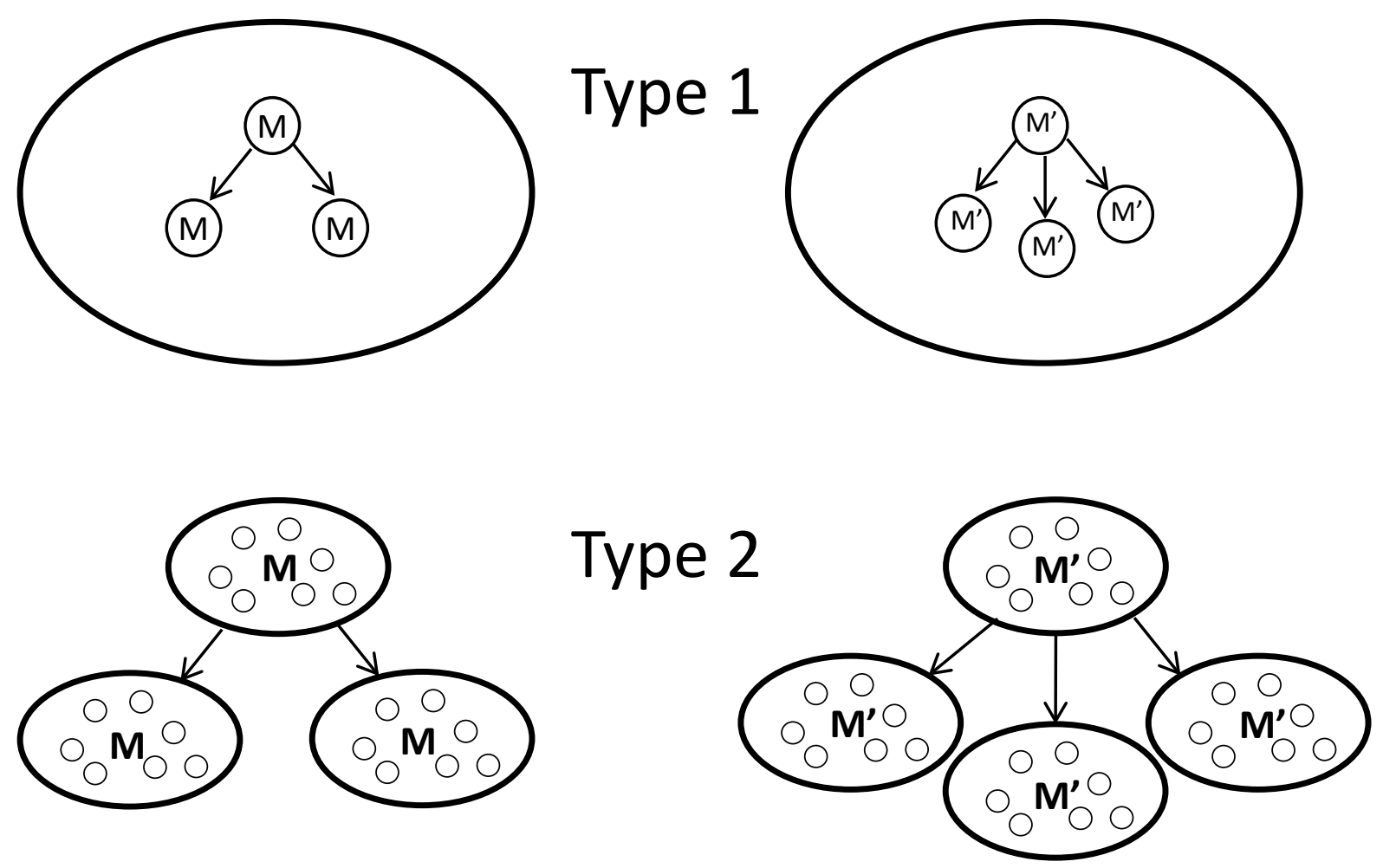